\author{
Carlos Casale Rolle
}

Profesor de la Facultad de Teología

Pontificia Universidad Católica de Chile

\title{
Wolfhart Pannenberg y el reto de la Modernidad: Pensar a Dios y al hombre desde la mediación (1)
}

A Peter Hünermann, con ocasión de la celebración de sus 77 años

En este artículo pretendemos mostrar cómo la teología de Pannenberg se puede entender como un desarrollo crítico y prospectivo del desafío que significa la filosofía de Feuerbach, en cuanto "maestro de la sospecha", para el quehacer teológico actual, pues este ya no puede analizar, estudiar e interpretar la palabra "Dios" en el contexto de la Modernidad sin ninguna explicación, so pena de caer en un discurso sin relevancia. Así pues, presentaremos la forma en que Pannenberg acepta el reto recién señalado y "defiende" la identidad y la relevancia del concepto de Dios en el campo de la filosofía, de la ciencia de la religión y, sobre todo, de la antropología. Para ello el teólogo de München elabora una consecuente "teología de la mediación" con pretensiones de ciencia.

\section{DEL POSITIVISMO TEOLÓGICO AL DESAFÍO DE FEUERBACH: HACIA UNA “TEOLOGÍA DE LA MEDIACIÓN” (2)}

Frente al reto perenne que constituye la obra de Feuerbach, algunos teólogos no encuentran dificultad alguna en situarse sobre el mismo terreno de aquel, es decir, el de la racionalidad filosófica y científica. A este tipo de reacción frente a la crítica de Feuerbach -y a lo que ella simboliza- la denominamos "teología de la mediación” (3). La característica fundamental de esta teología estriba en aceptar el

(1) Este artículo es el primer resultado de una investigación postdoctoral llevada a cabo en la Universidad de Tübingen (Alemania) durante los años 2002-2003 bajo la dirección del Prof. Dr. Peter Hünermann, y que contó con el apoyo financiero y humano de Stipendienwerk LateinamerikaDeutschland (ICALA).

(2) Todas las referencias bibliográficas en las notas que no llevan el nombre del autor son de Pannenberg, tanto como autor o editor.

(3) Con la denominación "teología de la mediación" no se hace referencia en nuestro estudio a un movimiento de teólogos protestantes del siglo XIX, sino a una intención más general de la teología. Como bien anota M. Xhaufflaire: “... el rasgo característico de las teologías de la 
reto del ateísmo moderno, partiendo de los mismos presupuestos de este: la antropología. De ahí su centro de interés: mediar racionalmente entre razón y fe, teología y antropología.

\section{La crítica al "positivismo teológico" de Barth}

Pannenberg, y esto es lo que queremos desarrollar en este estudio, es un representante destacado, a nuestro juicio, de la "teología de la mediación" (4). Este, en contra del "positivismo teológico" de K. Barth, afirma que "la teología debe aprender que, a partir de Feuerbach, no puede ya poner en su boca la palabra 'Dios' sin ninguna elucidación ulterior, que no puede seguir hablando como si el sentido de esa palabra fuera evidente de por sí, que, por tanto, no puede tampoco hacer teología desde 'arriba', como dice Barth, a no ser que se pretenda incurrir en el aislamiento desesperado y culpable de una glosolalia de orden superior y llevar a la Iglesia entera hacia un callejón sin salida [...] La lucha por el concepto de Dios ha de librarse ya sobre el campo de la filosofía, de la ciencia de la religión, de la antropología misma. Y si en este campo hubiera de concedérsele la razón a Feuerbach, entonces la prueba del ateísmo que él procuró, se habría finalmente llevado a cabo" (5).

Esta crítica a Barth es muy significativa para aprehender lo proprium de Pannenberg en esta temática, pues en aquello que se diferencia de un autor que se convirtió en un punto de referencia que ejerció una fuerza de atracción personal y

mediación es establecer contra Feuerbach, y en el terreno mismo en que este se ubica, la verdad y la validez de un momento propiamente religioso, del que la fe cristiana sería una explicación, una concreción. Asegurarse una posición de repliegue considerando que las 'traiciones religiosas y filosóficas' de la fe están solas y desintegradas por la crítica feuerbachiana, constituye para ellas una especie de capitulación espiritual" (Feuerbach et la théologie de la sécularisation, Paris 1970, 320, cursiva C.C.). Cf. el número monográfico 1-2 del año 2001 de la revista Teología y Vida, que recoge los trabajos y discusiones del "Seminario Interno de Profesores" de la Facultad de Teología de la Pontificia Universidad Católica de Chile llevado a cabo el año 2000 sobre el tema "La teología y sus mediaciones"; las reflexiones que aquí desarrollamos le deben mucho a aquel Seminario.

(4) Cf. los juicios, en la misma dirección de, J. Werbick, Der Streit um die "Natürliche Theologie" -Prüfstein für eine Ökumenische Theologie?, Catholica 37 (1983), 119-132; K. Koch, Der Gott der Geschichte. Theologie der Geschichte bei Wolfhart Pannenberg als Paradigma einer philosophischen Theologie in ökumenischer Perspektive, Mainz 1988, 18. 177-178. 206. 274; L. B. Puntel, Das Verhältnis von Philosophie und Theologie. Versucht einer grundsätzlichen Klärung, en: J. Rols-G. Wenz (eds.), Vernunft des Glaubens. Wissenschaftliche Theologie und kirchliche Lehre (FS Wolfhart Pannenberg), Göttingen 1988, 11-41; H. P. Willi, Dogmatik als Lehre von Gott, Theologische Beiträge 22 (1991), 102-110; P. Boschini, Kerygma e storia. La critica di W. Pannenberg a R. Bultmann, Filosofía e teología 3 (1989), 575-595.

(5) Typen des Atheismus und ihre theologische Bedeutung, en: Grundfragen systematischer Theologie. Gesammelte Aufsätze, vol. 1, Göttingen 1967, 351-352; ver las interesantes reflexiones que realiza M. Menke-Peitzmeyer, a propósito de la crítica de Pannenberg al "decisionismo" y "positivismo" barthiano en, Subjetivität und Selbstinterpretation des dreifaltigen Gottes. Eine Studie zur Genese und Explikation des Paradigmas "Selbstoffenbarung Gottes" in der Theologie Karl Barths, Münster 2002, especialmente 564-573; cf. también, M. Kappes, “Natürliche Theologie" als innerprotestantisches und ökumenisches Problem? Die Kontroverse zwischen E. Jüngel und W. Pannenberg und ihr ökumenischer Ertrag, Catholica 49 (1995), 276-309, especialmente $297 \mathrm{ss}$. 
teológica tan fuerte en la teología -sobre todo evangélica de habla alemana- a partir de la segunda mitad del siglo XX, es donde aparecerán los perfiles propios temáticos y formales de su reflexión (6).

Pannenberg hace notar que es entendible el que Barth se opusiera vehementemente contra el procedimiento de subordinar metódicamente la realidad de Dios a la realidad de la religión, pues de esa forma se renunciaba irreparablemente a la realidad de Dios. De esta manera, tanto la fe cristiana como la comprensión religiosa que de sí mismas tienen otras religiones, parten del primado de la realidad divina y de su automanifestación frente a todo culto humano de Dios. En este contexto Pannenberg le halla razón al teólogo de Basilea cuando este defiende que con el primado de la realidad de Dios y de su revelación frente a la religión lo que está en juego es la divinidad de Dios.

Sin embargo, en el contexto de la situación sociocultural que se ha desarrollado con la Modernidad, no se puede hacer valer dicho primado, subraya Pannenberg, sin "mediaciones" ("nicht unvermittelt") (7), pues de lo contrario el intento tendrá ya desde un inicio la forma de las aserciones puramente subjetivas, por más que estas se presenten como realizadas en nombre de una institución bajo el título de Dogmática "eclesiástica". El modo absoluto de este tipo de aseveraciones resulta así difícilmente diferenciable de otros fundamentalismos de diverso tipo (8). Señala Pannenberg que para hacer valer el primado de la divinidad de Dios frente a cualquier religión de un modo argumentativamente sostenible hay que recurrir a una "mediación argumentativa" ("argumentativen Vermittlung") (9) en lugar de a "afirmaciones no mediadas" ("unvermittelten Behauptens") (10). La "asunción y superación" (Aufhebung) de la religión en la revelación de Dios, con que Barth titula el largo y denso $\$ 17$ de la Dogmática Eclesiástica (11), no se logra, según Pannenberg, con afirmaciones "dogmáticas" ni con contraposiciones tajantes, del tipo de la "teología dialéctica": hay más bien que entrar argumentativamente en la problemática que ha llevado, a partir de la Ilustración, a que el concepto de religión llegara a ser central en la fundamentación de la Dogmática.

(6) El diálogo crítico con Barth está presente en toda la obra de Pannenberg, cf. por ejemplo, Problemgeschichte der neueren evangelischen Theologie in Deutschland, Göttingen 1997, 168204; Systematische Theologie, vol 1, Göttingen 1988, 58-72. 141. Una aproximación a las diferencias entre Barth y Pannenberg las ofrecen, N. H. Gregersen, Wolfhart Pannenbergs Beitrag zu einer trinitarischen Schöpfungslehre, Kerygma und Dogma 45 (1999), 102-129; P. d. Vitiis, Onto-Teologia e logica hermeneutica, Archivo di filosofia 48 (1980), 13-35; G. Accordini, Linguaggio, logica ed epistemologia nel pensiero di W. Pannenberg, Studia patavina 35 (1988), 342-361; íd., La rivelazione di Dio come storia e come atto. Scenari e codici nella teologia di W. Pannenberg, Milán 2002; G. L. Brena, Teologia e Modernità, Rassegna di Teologia 43 (2002), 441-455.

(7) Systematische Theologie 1, 142; cf. Die Religionen als Thema der Theologie, en: Beiträge 1, $160-172$.

(8) Cf. Systematische Theologie 1, 58ss.

(9) Systematische Theologie 1, 142; cf. Den Glauben an ihm selbs [sic] fassen und verstehen. Eine Antwort, Zeitschrift für Theologie und Kirche 86 (1989), 355-370, donde habla de la necesidad de una "gedankliche Vermittlung" entre teología y razón (364).

(10) Systematische Theologie 1, 142.

(11) Cf. K. Barth, Die Kirchliche Dogmatik I/2, § 17, Zurich (7) 1983, 304-396. 
Para Pannenberg, que ha estudiado detenidamente, incluyendo la perspectiva histórico-política, la génesis y configuración de esas condiciones (12), estas pueden señalarse como la disolución de la doctrina de la inspiración y la destrucción o reducción antropológica de la teología natural, cuyo cenit de esto último es Feuerbach. Junto con esto, señala Pannenberg, hay que hacer una valoración positiva de los elementos de verdad que se contienen en el moderno concepto de religión. Estos se relacionan precisamente con un aspecto central que Barth constata solo polémicamente: desde el paso del siglo XVIII al XIX la antropología ha llegado a ser el ámbito, el contexto, el horizonte en el que se toman las decisiones sobre el carácter universalmente vinculante o puramente subjetivo de cualquier lenguaje sobre Dios. Pannenberg constata que esta situación tampoco ha sido modificada por Barth, pues si se la tiene presente no se puede aceptar como correcto lo que este sugería con motivo de aquella "inversión de la relación entre revelación y religión”, que él juzgaba con razón como problemática: que la teología protestante se hubiera vuelto insegura en relación a una idea que había estado tan clara para los Reformadores, en cuanto que la decisión sobre el hombre ha sido tomada de una vez por todas y desde todos los puntos de vista en Jesucristo. Barth sabía muy bien que también los teólogos protestantes recientes habían dicho lo mismo. Ahora bien, se pregunta Barth, ¿contaban realmente con que eso es de hecho así? Barth lo ponía en duda, según Pannenberg, sin razón suficiente. En este contexto este último trae a colación a Schleiermacher (como ejemplo de otros pensadores de esa época con análogas pretensiones), un pensador que ha influido profundamente en la estructura formal de la teología pannenbergiana, que se empeñó con toda fuerza y rigor intelectual en hacer valer aquella "idea tan clara" citada por Barth en medio de las condiciones filosóficas y teológicas de su tiempo (13). Puede que la propuesta de Schleiermacher sea criticable, pero debe ponerse igualmente en el tapete de la discusión la tarea a la que intentó hacer frente: ¿de qué forma consigue la teología hacer entendible la primacía de Dios y de su manifestación en Jesucristo y hacerlo valer aspirando a sostener su verdad en una época en la que, casi por principio, todo discurso sobre Dios (teo-logía) se haya reducido, recortado a lo subjetivo, como señala tanto el devenir histórico social de la Modernidad como el destino moderno de las pruebas de la existencia de Dios y de la teología filosófica? (14).

(12) Cf. Theologie und Philosophie. Ihre Verhältnis im Lichte ihrer gemeinsamen Geschichte, Göttingen 1996, 129ss.

(13) Sobre la influencia de Schleiermacher en Pannenberg, cf. Systematische Theologie 1, 119ss. 140ss. 169ss; Theologie und Philosophie, 239-256; Problemgeschichte, 46-76; Religiöse Erfahrung und christlicher Glaube, en: Beiträge 1, 132-144.

(14) Cf. Systematische Theologie 1, 42-143; Systematische Theologie, vol. 2, Göttingen 1991, 61ss. P. O'Callaghan ha mostrado muy bien la distancia que Pannenberg toma de Barth en su acercamiento a Schleiermacher, Whose Future? Pannenberg's Eschatological Verrification of Theological Truth, The Irisch Theological Quarterly 66 (2001), 19-49, sobre todo 21ss. 


\section{El desafío de Feuerbach a la teología}

\subsection{Feuerbach como punto de inflexión de la filosofía de la "sospecha"}

Frente a las estrecheces de la teología de corte barthiano -y bultmaniana de tipo kerygmático (15) - y al reto de una teología que tiene la pretensión de exponer su identidad -el Dios de Jesucristo, la encarnación, la Trinidad (16)- con relevancia frente a las condiciones de la Modernidad (17), el propósito de Pannenberg se presenta doble. Por una parte, afirmar la realidad de Dios, pues la teología es "teología", ciencia de Dios (18). Pero, por otra, admitir la mediación antropológica de la manifestación de Dios. Razón por la que Pannenberg toma a Feuerbach como punto de referencia para exigir una justificación racional y antropológica de la idea de Dios frente al ateísmo moderno. La justificación racional de la idea de Dios es previa a la fe en Dios. De ahí que la necesidad de dicha justificación requiera plantear el problema sobre la necesidad de la teología filosófica como "lugar propio" de la justificación de la idea de Dios y anterior al lenguaje sobre Dios desde el punto de vista de la revelación. La delimitación del campo desde el que se puede llevar a cabo la justificación de la idea de Dios pertenece, pues, a la filosofía. Pero señalará Pannenberg a la filosofía moderna, ya que es en esta donde se ha planteado el problema de Dios de una manera totalmente nueva, hasta el punto de constituirse punto de partida del ateísmo moderno (19). En otras palabras, el intento, por parte de la teología, de justificar racionalmente la idea de Dios, no solo ha de tener en cuenta el hecho de la Modernidad, sino que debe moverse dentro de sus propios

(15) Cf. P. Boschini, Kerygma e storia, 575-595.

(16) Se puede afirmar que todas las reflexiones filosóficas, científicas y antropológicas de Pannenberg que conducen a conceptos "marco" de Dios, son desarrolladas en "perspectiva" teológica, y están al "servicio" de la exposición del contenido central del dogma, la Trinidad, de forma razonable para el hombre moderno -de ahí el carácter "misionero", desde sus inicios, de la teología según Pannenberg (cf. Das Ende der Metaphysik und der Gottesgedanke, en: Metaphysik und Gottesgedanke, 7-20, especialmente 12-13; Religion und Metaphysik, 48)- y no tienen, como a veces se sospecha, el carácter o la pretensión de ser un reemplazo de la realidad misma de Dios por una "idea" de Dios, sin que ello sea óbice a la crítica que se le pueda y debe hacer a Pannenberg sobre la forma como relaciona sus conceptos marco de Dios con la realidad del Dios de la revelación. Un ejemplo de aquel "servicio" lo constituye la asimilación teológico-trinitaria de la reflexión sobre la relación entre lo finito y lo infinito en la filosofía moderna (por ejemplo Hegel, Schleiermacher, Schelling). Para esta problemática cf. W. Schulz, Sein und Trinität, St. Ottilien 1997, 423-505.

(17) Esto ha sido puesto de relieve sintéticamente por G. L. Brena, La Teologia di Pannenberg. Cristianesimo e modernità, Casale Monferrato 1993.

(18) Cf. los largos desarrollos de esta idea en Systematische Theologie 1, 11ss.

(19) Como bien anota Pannenberg en su obra Una historia de la filosofía desde la historia de Dios, el viraje hacia la antropología empezó a convertirse en un programa en el llamado hegelianismo de izquierda, que se constituyó en el signo fundamental del conjunto de la filosofía posterior a Hegel y el verdadero humus a partir del cual han ido desarrollándose las más diversas corrientes de la filosofía hasta hoy. A partir de ese cambio, el fundamento para la comprensión del universo y la sociedad humana se desplaza de Dios (o el absoluto) al hombre mismo. Y el problema de fondo, ya no estriba en que si la conciencia de Dios tenga su origen en la autoconciencia humana, sino que Dios se reduce a ser una simple "idea" -o en el lenguaje de los "maestros de la sospecha", una mera "proyección"- del hombre (cf. Theologie und Philosophie, 294ss; Systematische Theologie 1, 97ss). Ver además, M. Kappes, “Natürliche Theologie”, 297ss. 
planteamientos. Ahora bien, puesto que el campo propio y específico de la teología filosófica de la Modernidad es la antropologización de la idea de Dios, corresponderá también a una teología que quiera ser seria y dar cuenta de los desafíos del presente (20), recurrir a la concentración antropológica como vía de acceso privilegiada a Dios.

Pannenberg subraya que para la teología filosófica de la Edad Moderna la dirección a seguir viene indicada por el conocimiento de que la naturaleza ya no conduce a ningún camino seguro a Dios, y por tanto todo el peso de la demostración ("die ganze Beweislast") de la verdad de la fe en Dios ha recaído en la comprensión del hombre, en la antropología (21).

La lucha de la teología por recuperar la "realidad" del concepto de Dios ya no puede esgrimirse recurriendo, por ejemplo, al "argumento cosmológico" -las modernas ciencias naturales están desarrollando un concepto de naturaleza que ya no necesita de la hipótesis de una primera causa del mundo- (22). La decisión última sobre la posibilidad de un lenguaje sobre Dios, entre teología como ciencia de Dios y el ateísmo, radica en la comprensión del hombre. La base o fundamento de la teología es así la antropología. De ahí que el núcleo de la pregunta de Pannenberg es de si la producción de una idea de Dios pertenece al ser del hombre o si es posible mostrarlo como un malentendido del hombre y por tanto como un error, que produce una "ilusión" y una falsa conciencia. Lo que se cuestiona, pues, no es si la idea de Dios es producto del espíritu humano, sino una idea, por tanto, que no es parte constitutiva de su autocomprensión, que pertenece a la esencia el hombre (23). Brevemente: “¿somos por naturaleza religiosos?” (24).

La primera forma de un ateísmo completo la constituye el ateísmo científicoreligioso de Feuerbach (25). La formulación originaria de su teoría sobre la religión se halla densamente compendiada en la siguiente frase: "La religión es la escisión (Entzweiung) del hombre consigo mismo: el hombre considera a Dios como un ser que le es opuesto" (26).

Este principio, afirma Pannenberg, encierra dos elementos: el concepto idealista, o más exactamente neohegeliano, del ser infinito del hombre y la idea hegeliana

(20) Desde un punto de vista neotestamentario hay que tener en cuenta el texto de 1 Pedro 3, 15; cf. M. Kappes, "Natürliche Theologie”, 307ss.

(21) Cf. Anthropologie und Gottesfrage, en: Gottesgedanke und menschliche Freiheit, Göttingen 1972, 11.

(22) Cf. Systematische Theologie 1,94-108.

(23) Cf. Anthropologie und Gottesfrage, 19.

(24) Así se titula una obra editada por Pannenberg, en la cual él mismo analiza aquella pregunta (Anthropologie in theologischer Perspektive. Philosopisch-theologische Grundlinien, en: Sind wir von Natur religiös?, Düsseldorf 1986, 87-105); cf. Anthropologie in theologischer Perspektive, Göttingen 1983; Macht der Mensch die Religion, oder macht die Religion den Menschen, en: Beiträge zur systematischen Theologie, vol. 2, Natur und Mensch-und die Zukunft der Schöpfung, Göttingen 2000, 254-259; Religion und menschliche Natur, en: ibíd., 260-269.

(25) Feuerbach ve su propio ateísmo inmerso en el proceso ideológico y necesario que, según él, comienza con el teísmo y, a través del panteísmo subsiguiente, termina finalmente en el ateísmo (cf. Philosophische Kriterien und Grundsätze, en: Sämtliche Werke (ed. W. Bolin), vol. II, Stuttgart (2) 1959, 223).

(26) Das Wesen des Christentums, (Reclam), Stuttgart 1998, 80. 
de la escisión o alienación (27). Esto nos conduce a unas breves reflexiones sobre el desafío de pensar la libertad del hombre frente a Dios a partir del reto de Feuerbach.

Feuerbach va a hacer, en primer lugar, una descripción, que podría denominarse fenomenológica y sociológica, del Dios presupuesto o imaginado por el hombre corriente. Se trata de un Dios vivido y pensado como "negación" del hombre. Dado que se trata de un espacio o ámbito único que han de compartir Dios y el hombre o el mundo, la lógica de esta relación inversa llevará a Feuerbach a sostener que la afirmación de la realidad de un Dios absoluto e infinito invadiría totalmente el espacio del hombre. El hombre y la divinidad no caben, pues, conjuntamente en el mismo lugar. Y por ello, el vaciamiento del mundo real y la plenificación de la divinidad es un mismo acto, como afirma en la Esencia del Cristianismo. De aquí que sea necesario optar o por la divinidad o por el hombre: Feuerbach no dudará en optar por el hombre frente a un concepto de divinidad para él inaceptable.

A Feuerbach le interesa más bien lo divino que Dios. Y, dado que teísmo y ateísmo hacen referencia más a Dios que a lo divino, es ya, en definitiva, poco importante o significativo que uno se denomine a sí mismo teísta o ateo: "Lo decisivo es lo que uno entiende por Dios [...] Todo depende únicamente del contenido, del fundamento y del espíritu, tanto del teísmo como del ateísmo" (28). Ahora bien, el contenido del "teísmo" analizado por Feuerbach no es para el "divino". "El teísmo, la fe en Dios, es de signo negativo: niega la naturaleza, el mundo y la humanidad". Por otra parte, el ateísmo por el que opta Feuerbach quiere ser un ateísmo humanista, comprometido con los hombres todos, un ateísmo "positivo y afirmativo, que devuelve a la naturaleza y a la humanidad la significación y la dignidad que el teísmo les había quitado, que vivifica de nuevo a la naturaleza y a la humanidad, a la que el teísmo les había chupado sus mejores energías" (29).

Por ello no se comprende en modo alguno el sentido del ateísmo feuerbachiano si este es pensado de manera directa como negación de Dios y no, más bien, como positiva y explícita afirmación del hombre (30).

(27) Para Pannenberg la cuestión nuclear del ateísmo moderno es la de la libertad del hombre: Dios muere y el hombre se libera. El "padre" (aquí utilizamos la expresión padre con la intención irónica que le otorga Pannenberg en su viñeta, Der Kirchenvater des Atheismus, Deutsches Allgemeines Sonntagsblatt 37, 10-9-1972, 12) de esta manera de pensar es Feuerbach con su teoría de la religión como proyección, lo que conlleva a la pregunta central: “ ¿... excluye [...] la libertad del hombre la existencia de un Dios [...]? Esta parece ser la cuestión nuclear con la que se decide la suerte del ateísmo y cuya solución es la condición fundamental de toda justificación de cualquier lenguaje sobre Dios, si no suficiente por sí misma, sí necesaria" (Reden von Gott angesichts atheistischer Kritik, en: Gottesgedanke, 37). En Feuerbach se encuentra, en efecto, el "punto de inflexión" (Der Kirchenvater, 12) de la historia del pensamiento ateo. Su teoría psicológica del origen de la idea de Dios como proyección del hombre ofrece la explicación del fenómeno religioso que se convertirá en "axioma" de buena parte de la cultura contemporánea. La razón del éxito de este filósofo, según Pannenberg, está en su perfecto ajustamiento al momento histórico de la cultura europea: lo más convincente de su argumentación es el carácter antropológico (antropocéntrico) de lo que es la antropología feuerbachiana misma. Su concepción, señala Pannenberg, participa de la verdad que le corresponde a la moderna metafísica de la subjetividad (cf. Typen, 358).

(28) Vorlesungen über das Wesen der Religion, en: Sämtliche Werke, vol. VIII, 20-30.

(29) Ibíd, 357.

(30) Se trata, pues, de un ateísmo esencialmente antropológico o humanista. O, dicho todavía con más exactitud, se trata propiamente no de un ateísmo, sino de una resuelta opción por el hombre, de un 
Es interesante señalar que Feuerbach rechaza el concepto de un Dios como "cómoda" solución de cualquier incógnita natural y su rechazo a la precipitada atribución a Dios de los efectos o fenómenos meramente naturales, dado que de este modo la expresión "Dios" se convierte en "una palabra breve y cómoda, en la que los hombres resumen y compendian la realidad múltiple e infinita, para así dispensarse a sí mismos del esfuerzo por conocer e indicar detalladamente las razones" (31). Tal Dios es en realidad para Feuerbach un no-Dios, y los que mantienen semejante concepción de la divinidad están para él, de hecho, en el ámbito del "ateísmo o naturalismo" (32).

2.2 De la asunción crítica pannenbergiana de Feuerbach a la propuesta de una teología como ciencia

Podemos decir que el núcleo de la crítica de Feuerbach a la teología estriba en descubrir en esta última una mala interpretación de base, puesto que se piensa la realidad de un ser superior al hombre-individuo, sin darse cuenta que la esencia finita no es más que su propia esencia genérica e infinita. El resultado de esta "mala interpretación" ha sido una "ilusión alienadora" (33). Dios, por consiguiente, es la falsa conciencia de la esencia del hombre.

El objetivo de la crítica de Feuerbach es transformar la "onto-teología" en "onto-antropología", llevar a término el giro antropológico de la teología filosófica moderna (34), cuya forma específica es el ateísmo moderno, basado fundamentalmente en el "principio de inmanencia" (35). Según ese giro, todo pensamiento y lenguaje sobre Dios es únicamente pensamiento y lenguaje "del" hombre. Este "del" encontró su formulación definitiva en la "reducción antropológica" de Feuerbach: Dios no es más que la "proyección objetivada" de la esencia del hombre. Esta proyección tiene un doble aspecto. El positivo: la teología no es otra cosa que el propio interés del hombre; de aquí que Feuerbach explique la génesis de la religión y de la teología recurriendo a la "teoría del deseo" (36). El negativo: la teología es

decidido humanismo. De aquí que Feuerbach prefiera calificar incluso su propio ateísmo no como ateísmo, sino como "antropoteísmo" (Ausgewälte Briefe, en: Sämtliche Werke, vol. XII-XIII, 393), puesto que lo que únicamente se pretende es la dignificación o magnificación del hombre.

(31) Gedanken über Tod und Unsterblichkeit, en: Sämtliche Werke, vol. I, 202.

(32) Vorlesungen über das Wesen der Religion, 187.

(33) Cf. Anthropologie in theologischer, 258ss.

(34) Pannenberg observa la raíz histórica del giro antropológico de la teología filosófica moderna en el concepto escotista de la teología como "ciencia práctica" (cf. Wissenschaftstheorie und Theologie, Frankfurt 1987 [original de 1973], 231ss. 309).

(35) Cf. K. von Stosch, art. Immanenz, en: A. Franz et al. [ed.], Lexikon philosophischer Grundbegriffe der Theologie, Freiburg i. B. 2003, 203-204. Para una visión amplia y lúcida ver, M. SecklerM. Kessler, Die Kritik der Offenbarung, en: M. Seckler et al. (ed.), Handbuch der Fundamentaltheologie, vol. 2, Traktat Offenbarung, Tübingen (2) 2000, 13-40, sobre todo 14ss.

(36) Si Feuerbach rechaza la divinidad lo hará a partir de la constatación de que la divinidad no es sino una sustantivación de los deseos subjetivos humanos de felicidad. De manera precisa caracteriza en este sentido H. J. Braun la visión feuerbachiana de la creencia en la divinidad de este modo: "La fe procede no de razones suficientes, como se podría pensar en el ámbito de una filosofía racional de la religión, sino de deseos suficientes" (Studien und Strukturen Feuerbacher Religionskritik. Notizen zur religionsphänomenologischen Methodendiskussion, en: H.-J. Braun et al. [ed.], L. Feuerbach und die Philosophie der Zukunft, Berlín 1990, 110). 
pura ilusión porque al concepto de "Dios" no le corresponde ninguna realidad extrahumana. Pannenberg ve aquí los límites de una argumentación antropológica para probar precisamente la "realidad" de Dios, pues aun cuando los grandes pensadores de la Edad Moderna defendieran con razón su concepción de que el hombre no se puede entender adecuadamente en sí mismo en su subjetividad sin la hipótesis de Dios, esta hipótesis podría seguir siendo una ilusión ineluctable, inevitable; sería inevitable precisamente porque estaría arraigada constitutivamente en la naturaleza del ser humano (37), y sería, sin embargo, una ilusión si a la idea de Dios no le correspondiera nada fuera de ella (38). Argumentando solo antropológicamente, es decir, partiendo de la problemática de la idea que el hombre tiene en sí mismo, no se puede confirmar suficientemente la hipótesis de Dios como realidad. Tal hipótesis solo es convincente en la medida en que la idea de Dios, basada en la problemática de esta idea del hombre, tiene al mismo tiempo "poder iluminador" para la experiencia del mundo. Así, pues, la experiencia del mundo y el problema del "poder" que en la última instancia lo determina es hoy indispensable también para cualquier aseveración sobre la realidad de Dios. "Pero el acceso a la idea de Dios ya no sería dado inmediatamente a partir del mundo, sino solo a través del rodeo (Umweg) de la concepción que el hombre tiene de sí mismo y de su relación con el mundo" (39).

Como muy densamente lo expresa Pannenberg, todo discurso sobre Dios habrá de acreditarse siendo capaz de mostrar en la experiencia del mundo el poder divino de Dios, de tal modo que este poder se manifieste como lo que es en nuestras experiencias cotidianas (40); estas son para Pannenberg las "condiciones mínimas" (Minimalbedingungen) (41) a las que ha de dar cuenta una teología que pretenda ser tomada en serio. De esta forma sigue siendo plenamente posible un "concepto marco" (Rahmenbegriff) (42) filosófico de aquello a lo que merecidamente podemos llamar Dios. Si no se reconoce esta posibilidad, señala nuestro autor, se renuncia igualmente a cualquier posibilidad de reclamar justificadamente para el lenguaje cristiano sobre Dios alguna "validez general" (Allgemeingültigkeit) (43). La teología cristiana no puede menos, por eso, de querer que la filosofía no deje a la larga la tarea de formular principios críticos para el discurso sobre Dios (44).

De lo dicho cabe con todo hacer una distinción entre la "apertura" del hombre a la cuestión de Dios, la cual podría reducirse a un lenguaje puramente "expresivo" y "teocéntrico" (45), y el "conocimiento de Dios". Es desde este último punto de

(37) Cf. I. Kant, Kritik der reiner Vernunft (Meiner), Hamburgo 1971, sobre todo Die tranzendentale Dialektik, 334ss (A 293ss).

(38) Cf. ibíd., 334ss (A 239ss); ver también en ibíd., Das Ideal der reinen Vernunft, 548ss (A 568ss).

(39) Wissenschaftstheorie, 311

(40) Cf. Systematische Theologie 1, 120; Wissenschaftstheorie, 335ss.

(41) Systematische Theologie 1, 120.

(42) Ibíd.

(43) Ibíd

(44) Cf. ibíd; Offenbarung als Kategorie philosophischer Theologie, en: Beiträge 1, 242.

(45) Cf. Die Frage nach Gott, en: Grundfragen 1, 361-365. Pannenberg realiza la distinción entre "mera aseveración expresiva sobre Dios" y "enunciado teológico asertivo". En la primera "no se intenta hacer asertos sobre los hechos; en cambio, en el segundo, si bien no tiene por qué estar resuelto todavía si es verdadero o falso, sí es indudable que el objeto o hecho sobre el que se afirma algo tiene que ser distinguible del aserto mismo (cf. Wissenschaftstheorie, 329ss.). 
vista que Pannenberg insiste en el carácter científico de la teología en tanto ciencia, la cual debe moverse propiamente en el contexto de la experiencia del mundo totalidad, no en el de la pura subjetividad (como por ejemplo en la teología de cuño barthiano) (46). Se trata de llevar a cabo una "constatación veritativa" del lenguaje teológico.

\section{LA JUSTIFICACIÓN -Y LA NECESIDAD- DEL ESTATUTO CIENTÍFICO DE LA TEOLOGÍA}

Pannenberg subraya constantemente a través de su obra, que el objetivo (único) de la teología es Dios (47). Pero Dios no está presente en la experiencia humana como un sujeto entre otros, al modo de los objetos a la mano heideggeriano. ¿Cómo puede haber entonces una ciencia de Dios? Evidentemente, solo desde el presupuesto de que la realidad de Dios se nos ofrece junto con los otros objetos de la experiencia. Es, pues, accesible no de un modo directo, sino solo indirectamente (48). Ahora bien, ¿en qué objetos de la experiencia se ofrece Dios de un modo indirecto -al menos como problema- de manera que se los pueda considerar como huellas ("Spuren") de Dios? (49) La respuesta que ofrece Pannenberg -y que determina su gnoseología teológica- es: en todos. Esta respuesta, que únicamente tiene el valor de conjetura y que requiere, a su vez, una prueba y una confirmación, descansa en el mismo "concepto marco" de Dios como "la realidad que todo lo determina". Ahora bien, si por el término Dios se tiene que entender la realidad que todo lo determina -concepto formal de Dios (50)-, es necesario demostrar que todo está determinado por esta realidad y que es incomprensible en última instancia sin ella (51). El planteamiento filosófico del problema de Dios comienza en el instante mismo en que se interroga por la totalidad del ente. Por eso dirá Hegel que "la filosofía es teología y ocuparse de ella o más bien en ella es para sí culto divino". Dios es, por consiguiente, "el único objetivo de la filosofía", cuya tarea consiste "en ocuparse de Él, en reconocerlo todo en Él, referirlo todo a Él, así como en derivar de Él todo lo particular y justificarlo tan solo en la medida en que surge de Él, vive de su irradia-

(46) Cf. las importantes reflexiones sobre el peligro del subjetivismo en Systematische Theologie 1, 53-58.

(47) Cf. los capítulos primero y segundo de Systematische Theologie 1

(48) Cf. Wissenschaftstheorie, 303.

(49) Cf. ibíd., 304

(50) En un ensayo muy importante, Pannenberg señala cómo la idea explícita de la fórmula de Dios como "la realidad que todo lo determina" es el resultado de la crítica de la concepción politeísta en el pensamiento griego que tendía a la unidad de la realidad divina como base de la unidad del cosmos. Desde que en la teología patrística se encuentra el monoteísmo judío con la idea filosófica de la unidad de lo divino, el pensamiento occidental no ha abandonado nunca esta idea. Así pues la definición nominal del concepto de Dios como realidad que todo lo determina es un hecho ya dado (cf. Die Aufnahme des philosophischen Gottesbegriffs als dogmatisches Problem der früchristlichen Theologie, en: Grundfragen 1, 296-346; ver también, Wissenschaftstheorie, 305ss).

(51) Esta idea está ampliamente desarrollada en Systematische Theologie 1, 58ss. 
ción y tiene su alma en Él" (52). Dios es "el punto de partida y la meta final de todo; todo parte y retorna a Él" (53).

\section{El desarrollo hegeliano de la temática de la "totalidad": una idea clave de la teología de Pannenberg (54)}

A pesar de ser autores que responden a desarrollos filosóficos diversos, se puede rastrear la huella de Hegel, Schleiermacher y Dilthey -entre otros- en Pannenberg, en tanto se presentan como un desafío a la teología de pensar a Dios desde la perspectiva de la totalidad (los acentos podrán estar puestos en la historia, en el desenvolvimiento del Espíritu, pero en el fondo hay una tendencia a enfrentarse a la "totalidad" y, consecuentemente, a su interrelación con las "partes") (55). Nosotros creemos que los autores antes señalados han influido fuertemente en una de las intuiciones claves y fundamentales de Pannenberg: pensar desde la totalidad (aun cuando esta se nos dé solo como anticipación). Para ello presentaremos sintéticamente el planteo central de Hegel, que está subyacente, explícita e implícitamente, en toda la obra de Pannenberg, sin que ello sea óbice, a que este esté constantemente haciendo referencia a los límites de tal planteo en la teología (56).

Hegel ha vuelto a colocar con mucha insistencia en la filosofía el pensamiento en la dimensión del "todo" (57), que se convierte en base y fundamento del verdadero pensar filosófico, del pensar de la "razón" (Vernunft) en cuanto modo de pensar distinto de las "abstracciones" del mero "entendimiento", que no hace sino analizar, dividir o formalizar, de manera no "concreta", la realidad. Porque para Hegel lo que realmente interesa, lo verdadero, es lo "concreto", entendida esta expresión en su sentido radical y etimológico como lo que "crece conjuntamente" (concrescere) y, por lo tanto, como lo "total" y no meramente particular o parcial. De este modo

(52) Vorlesungen über Philosophie der Religion. Einleitung. Der Begriff der Religion, W. Jaeschke (ed.), Hamburg 1993, 33-34.

(53) Ibíd., 3.

(54) La utilización de la filosofía de Hegel en la teología es quizá una de las cuestiones más disputadas de la teología contemporánea. Más allá de todos los resguardos y críticas necesarias a tal utilización, aquí nos hacemos cargo de la opinión de L. Oeing-Hanhoff, en cuanto a que la necesaria "mediación" (Vermittlung) de la razón y la teología han encontrado en Hegel una "estación" invadeable para su elucidación, sobre todo cuando Dios y mundo ya no se pueden volver a pensar más allá de la historia y la libertad, dos conceptos claves de la filosofía actual (cf. Hegels Trinitätslehre. Zur Aufgabe ihrer Kritik und Rezeption, Theologie und Philosophie 52 [1977], 378-407).

(55) Un buen resumen de estas influencias lo expone Pannenberg en su ensayo Die Bedeutung der Kategorien "Teil" und "Ganzes" für die Wissenschaftstheorie der Theologie, en: Beiträge 1, 85100 .

(56) Cf. por ejemplo, Theologie und Philosophie, 285-293; Die Bedeutung des Christentums in der Philosophie Hegels, en: Gottesgedanke, 78-113, sobre todo 102ss; Die Bedeutung der Kategorie "Teil" und "Ganzes" für die Wissenchaftstheorie der Theologie, 85-100, en donde Pannenberg reconoce en este punto la influencia decisiva de Hegel, y se refiere a la categoría del "todo" en el sistema hegeliano como a "la categoría de todas las categorías" (99).

(57) Cf. los interesantes análisis comparativos, donde se destaca en este punto una cierta continuidad del planteo hegeliano con el tomista que realiza E. Brito, Dieu et l'être d'apres Thomas d'Aquin et Hegel, Paris 1991. 
conecta Hegel de hecho con Aristóteles ("el alma es en cierto sentido todas las cosas") (58), al ver de manera similar Hegel la "razón" como identificada con la totalidad de la realidad. Por ello insistirá Hegel, de una o de otra forma, en que -como escribe, por ejemplo, en el Prefacio de la Fenomenología del Espíritu- lo "verdadero es el todo" (59). Como el pensamiento de la divinidad vive de la atmósfera o dimensión de la "totalidad", nada extraño que Hegel, al haber identificado a la "razón" filosófica con la búsqueda del todo, que es lo único "verdadero", afirme también explícitamente que el específico objeto de la filosofía sea "Dios" y, por lo tanto, la filosofía sea realmente en este sentido "teología". De este modo Dios, como ya dijimos a propósito de las Lecciones sobre Filosofía de la Religión, se constituye en el único y exclusivo objeto de la filosofía, la que deviene, por tanto, teología.

Bien consciente era Hegel, desde luego, de que esta su actitud filosófica no estaba en la línea de la dominante moda filosófica, fuertemente asentada en el agnosticismo filosófico respecto de la divinidad heredado de Kant. Hegel no se arredra, sin embargo, ante ello, y desde su propia posición filosófica no deja asimismo de lamentarlo y de considerarlo bien aberrante (60).

Si la filosofía de Hegel, es, pues, en este sentido un grandioso intento de recuperación de la tradición teológica prekantiana en una época marcada y condicionada por el kantismo, hay que tener en cuenta que la filosofía hegeliana del espíritu absoluto, en coherencia lógica con su pasión por el "todo", no elabora de manera ingenua y precrítica una abstracta filosofía apriórica de la divinidad, deducida de simples y meros conceptos, sino que, precisamente por su preocupación por el "sistema" y por la visión de conjunto de la realidad, intenta mostrar en toda realidad, y de manera especial en el espíritu del hombre, la imagen o el efecto de su inclusión en el todo o de su relación con la realidad absoluta. Por ello puede decir Hegel -en sus Aforismos del período de Jena- de manera solo aparentemente contradictoria, en relación con su concepción del "todo": "No es lo esencial únicamente la visión de la dependencia de lo particular respecto del todo, sino que lo es también el que cada momento mismo, independientemente del todo, es el todo, y esto es el profundizar la cosa" (61). Si ello es así -es decir, si en cada "momento" puede en principio descubrirse filosóficamente el "todo"- se abre entonces el camino para una consideración y apreciación "realista", podríamos decir incluso antropológica, de multitud de reflexiones de Hegel sobre el hombre y la divinidad, que de entrada podrían ser consideradas como meramente ideales o conceptuales.

(58) De anima III, 8; 431 b 21

(59) "Das Wahre ist das Ganze" (Phänomenologie des Geistes, H.-F. Wessels-H. Clairmont [eds.], Hamburg 1988, 15). Más precisiones hegelianas sobre el sentido del "todo" se pueden confrontar, entre otros lugares, en Enzyklopädie der philosophischen Wissenschaften (1830), F. Nicolin-O. Pöggler (eds.), Hamburg 1991, § 14ss. El texto de la Enciclopedia resulta especialmente interesante, pues aquí se relaciona explícitamente lo verdadero o "sistemático" con el "todo" y lo "concreto".

(60) Cf. Vorlesungen über die Philosophie der Religion. Einleitung, 31ss.

(61) K. Rosenkranz, Georg Wilheim Freedrich Hegels Leben, Darmstadt 1971, 548 
2. La naturaleza hipotética del conocimiento de Dios como posibilidad de asertos sobre la divinidad.

Dios es la realidad que todo lo determina. Pero ¿de qué naturaleza es esta realidad? Pannenberg señalará que esta es hipotética, no dogmática. La razón que da este autor es que "la realidad de Dios solo se presenta siempre en anticipaciones subjetivas de la totalidad de la realidad, en modelos de totalidad de sentido, que acompañan a toda experiencia particular y que son a su vez históricos, es decir, que están sujetos a la confirmación o a la refutación en el curso de la experiencia. Según esto, el momento de la anticipación siempre implica también el de lo hipotético. Pero, por otra parte, en este momento hipotético se funda la historicidad de la copresentación (Mitgegebenseins) o manifestación de la realidad divina" (62). La tesis de Pannenberg está basada en una circularidad entre el "momento hipotético" y la "manifestación de Dios".

Ahora bien, es en esta circularidad donde radica precisamente la "mediación" de Dios por el hombre, puesto que la realidad divina, aun teniendo la iniciativa por su "acción" (63), es decir, por su "revelación", en tanto "automanifestación", está siempre "autocondicionada" (64) por el "carácter anticipativo de la existencia humana de sentido" (65), aunque sin ser "reducida" a este; de lo contrario, se "estaría en contradicción con la idea de Dios, en cuanto realidad que todo lo determina, si fuera accesible de otro modo que por su misma acción" (66). Lo sustancial de la tesis de Pannenberg consiste en hacer ver que no se trata de "reducir" la hipótesis de Dios a pura "proyección anticipativa" del hombre, sino de "mediar" históricamente la automanifestación de Dios por la problemática de la realidad de la experiencia finita, tal como es expresada en la historia de las religiones. Volviendo a Hegel (67), Pannenberg quiere poner en claro que no se puede "reducir" lo infinito a lo finito, pues se lo negaría; sino de "mediar" lo infinito "por" lo finito, tal cual es expuesto, entre otros lugares, en la Ciencia de la lógica (1832) y las Lecciones sobre filosofía de la religión (El concepto de religión), a los cuales haremos alusión más adelante. Esta mediación nos muestra precisamente el carácter histórico de la automanifestación de Dios. Y es aquí donde cumple una función importantísima la "historia de las religiones". En esta "se percibe explícitamente la automanifestación particular de la realidad divina a la experiencia humana" (68). De ahí su carácter de "teofanía". Lo cual no significa que la "historicidad" de la experiencia de Dios en las religiones es algo "complementario" al concepto de Dios; todo lo contrario, es "deducible" de la misma idea de Dios. Tanto es así que una determinada religión sería más "histórica" en la medida en que esté "fundamentada" en la "historicidad" de la automanifestación

(62) Wissenschaftstheorie, 312-313.

(63) Ibíd., 313

(64) Ibíd.

(65) Ibíd.

(66) Ibíd.

(67) Typen, 350-353. A Pannenberg le parece que es por la "vuelta" a Hegel como se puede llevar a cabo la confrontación con Feuerbach.

(68) Wissenschaftstheorie, 315-316. 
de Dios. Creemos que fue esta la razón principal que movió a Hegel a considerar al cristianismo como "religión absoluta o manifiesta". Lo fundamental del cristianismo estriba en que es la religión de la "encarnación de Dios" y, por consiguiente, de la mediación histórica interna de Dios (69). Pannenberg viene a decir lo mismo, pero con otras palabras: un rasgo peculiar de las religiones bíblicas podría consistir en que la historia de las experiencias religiosas y sus variantes en la tradición bíblica y en el cristianismo se ha hecho tema de la religión, campo de la automanifestación divina: "Este es el fundamento de que las religiones bíblicas pueden sobrevivir a la experiencia de su propia transformación histórica. Mientras que las religiones cuya conciencia está inspirada en una 'Edad de Oro' mítica -que se supone insuperabley en una consiguiente organización del mundo son barridas por su propia transformación histórica, la religión judía y la cristiana, como religiones de la historia (Geschichte), pueden integrar sus propias transformaciones y reconocer en ellas una guía divina" (70). Pero antes de concluir este punto y pasar a analizar las relaciones entre la teología y la ciencia de las religiones en Pannenberg, será necesario detenerse brevemente en lo que recién hemos insinuado sobre el tema del "infinito".

\section{El "verdadero infinito" (Hegel): hacia una aclaración del carácter mediador de la finitud en su encuentro con Dios en la teología de Pannenberg.}

Recién hemos hecho referencia a la cercanía crítica de Pannenberg a la idea del "verdadero" infinito en Hegel y su rol fundamental en la teología de la "mediación" que aquel intenta desarrollar actualmente (71). En prácticamente todo el tamiz de la teología sistemática de Pannenberg es posible encontrar esta idea hegeliana, sin la cual no se puede explicar el sentido profundo de lo que signifique la "mediación" entre teología y filosofía. Una pequeña revisión de los textos hegelianos sobre el infinito nos otorgarán una pista decisiva (72).

Junto con Schleiermacher (73), será sobre todo Hegel quien en este punto tenga una influencia temática y formal decisiva en la arquitectura teológico-filosófica de Pannenberg y que se puede rastrear explícita o implícitamente en toda su "sistemática" (74).

(69) Cf. G. W. F. Hegel, Phänomenologie des Geistes, 492-499.

(70) Wissenschaftstheorie, 316.

(71) En un ensayo como este no podemos desarrollar todas las otras influencias que en esta temática recibe Pannenberg. Valga aquí señalar la de Schleiermacher, Über die Religion (1799), G. Meckenstock (ed), Berlin 2001, 81 .

(72) Para esta temática en Hegel, cf. T. Koch, Differenz und Versöhnung. Eine Interpretation der Theologie G.W.F. Hegels nach seiner "Wissenschaft der Logik", Gütersloh 1967, sobre todo 106130; M. Theunissen, Hegels Lehre von absoluten Geist als theologisch-politischer Traktat, Berlín 1970, especialmente 39-42.

(73) Según Schleiermacher, el concepto de infinitud no debe ser definido primariamente como ilimitación: "Pues propiamente infinito no será aquello que no tiene fin, sino lo contrapuesto a lo finito, es decir, a lo codeterminado por otras cosas" (cf. Systematische Theologie 1, 429, con referencia a Der christliche Glaube $\$ 56,2$ ).

(74) La influencia de Hegel en este punto se puede confrontar en numerosos textos de Pannenberg, por ejemplo, Systematische Theologie 1, 117ss. 188ss; Theologie und Philosopie, 257-293; Problemgeschichtliche, 260-290; Die Bedeutung des Christentums, 78-113. 
Será Hegel quien eleve a su más alto grado el pensamiento sobre la relación entre lo finito y lo infinito, en donde el infinito o el absoluto vienen a ser en él la denominación filosófica de la divinidad teológica. Temática esta a la que le concede máxima importancia, al indicar él mismo que "la naturaleza de lo finito e ilimitado y, por lo mismo, su relación con lo infinito constituyen el punto más difícil, el objeto único -se podría decir- de la filosofía" (75).

El joven Hegel veía ya en tal relación la impronta o vertiente natural y filosófica del haberse Dios hecho hombre, un hecho que afecta a la "vida" entera del hombre y que no puede ser abordado desde la mera reflexión del "entendimiento" al margen de la "razón" que piensa desde el todo (76). Como se ve, Hegel intentará tomar en serio esta misteriosa conexión de la finitud con la infinitud, poniendo el acento en la imposibilidad de pensar lo finito en cuanto finito desde el mismo ámbito finito.

Para Hegel el infinito es la condición misma de posibilidad de lo finito. No puede ser pensado como un "más allá" de este, lo que significaría una contradicción del infinito consigo mismo. El infinito hegeliano es así "el verdadero (wahre) infinito", que es calificado por él como el "concepto fundamental" de la filosofía (77). Lo contrario del mismo es "la mala o negativa (bloß schlechte) infinitud" (78). Ambos conceptos se contraponen entre sí de la misma manera que se contraponen mutuamente "razón" y "entendimiento" (en el sentido que ambos tienen en Hegel): "Lo principal es distinguir el verdadero concepto de infinitud de la mala infinitud, lo infinito de la razón (Vernunft) de lo infinito del entendimiento (Verstandes)" (79).

Pues bien, el "infinito malo" o el infinito del "entendimiento" es en realidad un "infinito finitizado", dado que, en la medida en que es considerado como desligado o apartado de lo finito, queda él mismo finitizado y deja de ser, en consecuencia, verdaderamente infinito. Este no puede ser pensado como si lo finito estuviese "fuera" o "debajo" de él (80) o "frente" a él, ya que de ese modo viene a ser el infinito un "infinito finito" (81). El infinito se desinfinitiza al tener su "frontera" en el finito y surgen, por así decirlo, “dos finitos” (82).

Desde el punto de vista de lo finito lo que ocurre resulta también contradictorio, si se piensa la relación finitud-infinitud según el modelo de la "mala infinitud". Porque en tal situación no solo se finitiza lo infinito, sino que lo finito mismo

(75) Ein Hegelsches Fragment zur Philosophie des Geistes, F. Nicolin (ed.), Hegel Studien 1 (1961), 28.

(76) "El Hijo de Dios es también el hijo del hombre: lo divino aparece como hombre en una figura determinada; la conexión de lo finito con lo infinito es evidentemente un misterio sagrado, porque esta conexión es la vida misma; la reflexión, que separa la vida, puede dividirla en infinito y finito, y la limitación, lo finito considerado en sí mismo, presenta el concepto de hombre como contrapuesto al de lo divino; fuera de la reflexión, en la verdad, ello no es así" (Hegels Theologische Jugendschriften, H. Nohl (ed.), Tübingen 1907, 309s).

(77) Enzyklopädie, §95.

(78) Ibíd., § 94.

(79) Wissenschaft der Logik. Erster Teil: Die objetive Logik. Ersten Band : Die Lehre vom Sein (1832), F. Hogemann-W. Jaeschke (eds.), Hamburg 1985, 124.

(80) Cf. ibíd., 125

(81) Cf. ibíd., 127

(82) Cf.ibíd., 131ss. 
adquiere las características propias de la infinitud, al atribuírsele a lo finito "el mismo grado de independencia que al infinito; el ser de lo finito se convierte en un ser absoluto" (83). En realidad lo finito, al estar apartado o desligado de lo infinito, se convierte en verdadero "ab-soluto".

Dadas las contradicciones que conlleva la "mala infinitud", el único modelo explicativo válido de la relación entre finitud e infinitud es el de la "verdadera infinitud", por el que lo finito no está fuera o al margen de la infinitud. Es decir, lo finito pertenece de alguna manera también a la infinitud. La infinitud es de algún modo también "finita". En palabras de Hegel: "Dios es también lo finito y yo soy también lo infinito" (84). Es decir, no puede ser para Dios lo finito una dimensión extraña, en la que él encuentre su límite, ni el hombre puede estar apartado o desconectado del ámbito infinito, que posibilita justamente que el hombre sea el que es. Es precisamente en este contexto sistemático donde Hegel formula su conocida afirmación: "Dios no es Dios sin mundo" (85). Es decir, la divina infinitud no puede estar al margen de unas realidades que solo pueden constituirse como tales en virtud de ella y que no pueden existir sino "en el interior" de ella, si es que la "infinitud" es y permanece siendo lo que es.

No se trata, pues, en Hegel de una simple y burda identificación entre finitud e infinitud, sino de presentar un modelo de su mutua relación que haga justicia a su contenido, sin recaer en un mero juego de conceptos contrapuestos (el de finitud y su contrario, la infinitud). De aquí también la utilización por parte de Hegel de formulaciones aparentemente contradictorias, pero que no pretenden sino expresar la realidad misma de una relación única y fundamental, la relación entre finitud e infinitud, descrita por él, por ejemplo, como "identidad en diferencia" (86).

El modelo de la "verdadera infinitud" estructura lógicamente el modo cómo Hegel va a reflexionar sobre el conocimiento de la infinitud o de la divinidad por parte de la finitud humana. La crítica que Hegel va a dirigir contra la absolutización de la finitud del conocimiento humano -que implica la imposibilidad de acceder cognoscitivamente a lo que no sea meramente finito- es en realidad la misma que él formula al poner al descubierto las contradicciones inherentes a la "mala infinitud". Porque el "entendimiento" (a diferencia de la "razón"), al limitarse en sus posibilidades respecto del infinito, considera en realidad a este como finito (dado que apartado o alejado del "entendimiento", que no es afectado por él) y, al mismo tiempo y por la misma razón, se infinitiza o absolutiza inconscientemente a sí mismo (87). Este será también, por tanto, el punto central de la crítica de Hegel a la postura gnoseológica kantiana, que se instala en la radical finitud del conocimiento humano.

(83) Cf. Enzyklopadie, §95.

(84) Vorlesungen über die Philosophie der Religion. Einleitung, 212-213.

(85) Ibíd., 213.

(86) Cf. ibíd., 193-215. "Esta unidad de lo infinito y lo finito y su distinción son tan inseparables como la finitud y la infinitud" (Wissenschaft, 145).

(87) Enzyklopadie, §95. 
Hegel pone de relieve frente a Kant (88), como bien lo asume Pannenberg en sus análisis (89), que es justamente la misma dialéctica inherente a lo finito, que proviene de su no estar "apartado" del "verdadero infinito" y de no ser este para él verdadera "frontera" delimitante, la que se muestra en el conocimiento humano. Por el contrario, el "dualismo kantiano", que no ha accedido a la "verdadera infinitud", no puede menos de mostrarse incapaz de superar la dimensión finita. Pero lo que en este contexto Hegel considera con razón como "la mayor de las inconsecuencias" es el "conceder, por una parte, que el entendimiento solo conoce lo fenoménico (Erscheinungen), y considerar, por otra, este conocimiento como absoluto, al decir: el conocimiento no puede más, este es el límite natural, absoluto, del saber humano" (90). Hegel descubre así la oculta y fundamental contradicción de todo pensamiento que se califica a sí mismo como radicalmente finito, como clausurado en su propia finitud. En efecto, al adoptarse tal postura, ¿no se pisa ya de hecho terreno no relativo o finito, dado que tal afirmación tiene pretensiones de validez universal o absoluta?

Hegel retomará aquí, además, de la tradición prekantiana contra la postura kantiana un modo de argumentar que, en cuanto a su contenido, estaba ya presente -como sabemos- en el pensamiento cartesiano. El decisivo pasaje hegeliano es el siguiente:

"Las cosas naturales son limitadas, y solamente lo son las cosas naturales, en cuanto que ellas no saben nada de su límite general, en cuanto que su determinación es solo límite para nosotros, no para ellas. Solo se conoce o siente algo como límite, como falta, en cuanto que se está al mismo tiempo más allá [de ellos] [...] El límite, la imperfección del conocer solo es concretizable como límite o imperfección en virtud de la comparación con la idea presente de lo general, total y perfecto. No es, por lo tanto, sino inconsciencia el no ver que precisamente la denominación de algo como finito o limitado contiene en sí la prueba de la presencia real de lo infinito, ilimitado, de que solo es posible el conocimiento del límite en cuanto que lo ilimitado está del lado de acá [diesseits] en la conciencia" (91).

En esto consiste, pues, lo dialéctico de la finitud humana, que precisamente para poder afirmarse a sí misma como tal necesita colocarse, por así decirlo, en

(88) La crítica de Hegel se dirige no solamente a la filosofía kantiana en sí, sino, sobre todo, a la actualidad de su influjo. Justamente en el contexto de la importancia concedida a la unión entre lo finito y lo infinito se lamentará Hegel de la subordinación de la "razón" al "entendimiento", que recluye a la divinidad en el ámbito de lo desconocido: "El entendimiento de la época reciente ha convertido a Dios en una abstracción, en un más allá de la autoconciencia humana, en una muralla plana, de hierro, contra la que el hombre no hace sino romperse la cabeza. Pero la razón tiene ideas completamente distintas de las abstracciones del entendimiento" (Die Vernunft in der Geschichte, J. Hoffmeister [ed.], Hamburg 1955, 126).

(89) Cf. Theologie und Philosophie, 257ss.

(90) Enzyklopädie, § 60. Cf. los análisis de Pannenberg al respecto en, Theologie und Philosophie, 257 ss.

(91) Enzyklopädie, § 60. Esta idea fundamental hegeliana de la conciencia del límite como superación del mismo es expuesta ya en Wissenschaft, 118 ss. 
cierto sentido "fuera" de ella misma, es decir, percibir o "conocer" aquello que no es finito, según el principio tradicional de que la limitación es negación de una perfección o positividad ulterior. Frente a la conciencia de esta dialéctica está, sin embargo, la inmovilidad o "fijación" con la que el "entendimiento" concibe la finitud, al considerarla como dimensión insuperable y última, juzgando al mismo tiempo que es "una temeridad y una locura la del pensamiento que quiera superarla" (92). Pero la réplica de Hegel a esta postura en sus Lecciones sobre filosofía de la religión no se deja esperar: "Tal modestia del pensamiento, que hace de lo finito algo simplemente fijo y absoluto, es la peor de las virtudes". Esa presunta "humildad" -según se indica en otro pasaje paralelo-, "que renuncia a todo conocimiento del ser en sí y que no quiere conocer nada de Dios [...] es la refutación de sí misma; semejante humildad es, más bien, soberbia". La razón de la inconsecuencia y falsedad intrínseca de esta "humildad" del "entendimiento" está en su interna contradicción: en la renuncia del "entendimiento" al conocimiento del ser en sí y de Dios se está autoafirmando a sí mismo de modo absoluto; para él la verdad es el "yo". Por el contrario, "la verdadera humildad renuncia a su propio yo [...] y reconoce únicamente como lo afirmativo a lo verdadero y al ser en sí y para sí [...] La falsa humildad, en cambio, [...] convierte lo finito en lo afirmativo, infinito y absoluto: yo [...] soy lo único esencial; es decir, yo, lo finito, soy lo infinito, el mismo ser en sí y para sí”. En resumen: "El yo se finge humilde, mientras que en su soberbia [...] no sabe desprenderse de sí mismo" (93).

Como se ve, el anti-“subjetivismo" de Hegel (como, antes, el cartesiano) es lógica consecuencia de la primariedad y fundamentalidad del infinito en el conocimiento humano, tal como había sido defendida por Descartes. Aunque, en relación con Descartes, es justo reconocer que Hegel, en su intento de frenar la avalancha destructora de la posibilidad del conocimiento de la divinidad, provocada por el kantismo, pudo excederse -según han señalado bastantes de sus críticos- en sus especulaciones relativas al conocimiento del infinito, más allá de la ponderada cautela cartesiana respecto del infinito, que es para Descartes "entendible", pero en modo alguno "comprehensible".

\section{CONCLUSIONES}

¿Qué conclusiones se pueden sacar de las consideraciones anteriores, en vistas al problema de la "cientificidad" de la teología? Si como se ha afirmado antes, la totalidad de sentido (94), en tanto manifestación "histórica" de la realidad problemática de Dios se hace explícita en la historia de las religiones, la conclusión que saca Pannenberg es que "la teología, como ciencia de Dios, solo es posible como ciencia de la religión, y precisamente no como ciencia de la religión en general, sino de las

(92) Enzyklopädie, § 386

(93) Vorlesungen über die Philosophie der Religion. Einleitung, 201-202.

(94) Cf. Systematische Theologie 1,167ss. 
religiones históricas" (95). Pero el razonamiento de Pannenberg no se para aquí; dice algo más importante: la investigación de las religiones históricas tiene un carácter teológico "solo si interroga a las religiones hasta qué punto está documentada en sus tradiciones la automanifestación de la realidad divina” (96). Es este precisamente el punto de vista que sirve para demarcar el quehacer propio de la "teología de la religión" con respecto a una sicología o una sociología de la religión, e incluso de una fenomenología de la religión entendida como simple comparación y ordenación -fenomenología descriptiva-comparativa- de los fenómenos religiosos. La teología considera a los enunciados religiosos como "hipótesis de totalidad", hipótesis que tienen que ser sometidas a "control" "sobre la base del contexto de la experiencia actualmente accesible" (97), con el fin de hacer ver "hasta qué punto esas afirmaciones transmitidas de una religión determinada pueden integrar la multiplicidad de la experiencia actual" (98).

\section{LA RELACIÓN "POSITIVA" ENTRE TEOLOGÍA Y CIENCIA DE LAS RELIGIONES. EL CARÁCTER “TEOLÓGICO” DE LA CIENCIA DE LAS RELIGIONES}

Una de las posiciones fundamentales de la "Escuela de la historia de las religiones" a la hora de establecer la relación entre religión y revelación es invertir la religión a la revelación. Por esto una teoría general de la religión y de su evolución histórica es anterior al estudio sobre la religión (así por ejemplo, E. Troeltsch, A. v. Harnack y el neoprotestantismo). En cambio la posición de la teología dialéctica de K. Barth cambia las relaciones entre religión y revelación: explicar la religión desde la revelación. Aquí radica propiamente el problema teológico de la ciencia de las religiones (99).

¿Cómo plantea Pannenberg este problema? (100) Está de acuerdo con la intención de la tesis de Barth: la teología no puede detenerse en exponer la experiencia y el comportamiento humano, sino que su verdadero tema es el problema de la realidad de Dios y su manifestación (101); pero no lo está en la manera de relacionar la manifestación de Dios (revelación) con la religión. En contra de la prioridad y oposición de la revelación con respecto a la religión (Barth), es decir, en contra de la pureza de la revelación de Dios, Pannenberg defiende que es imposible considerar a priori la revelación divina por sí misma -por así decirlo, antes de toda religión

(95) Wissenschaftstheorie, 317.

(96) Ibíd.

(97) Ibíd.

(98) Ibíd., 318.

(99) Cf. K. Barth, KD I/2, § 17.

(100) Para el planteamiento del problema cf. Wissenschaftstheorie, 303-329; Systematische Theologie 1, 133-201; Beiträge 1. Aquí no podemos desarrollar la crítica que se le ha hecho a este planteo de Pannenberg, para ello cf. A. Lange, Religion als Weltbemächtigung. Zur Begründung der Theologie durch die Theorie der Religion bei Wolfhart Pannenberg, Gütersloh 2003; W. A. Euler, Wolfhart Pannenbergs Theologie der Religionen, Trier Theologische Zeitschrift 107 (1998), 173190.

(101) Cf. Wissenschaftstheorie, 321. 
humana- y contraponerla a esta última (102). La manifestación de Dios está siempre mediada por la religión. El creyente, desde luego, abrazará en su tradición religiosa la revelación de Dios y no solo una religión humana. Si se da una prioridad de Dios con respecto a la subjetividad religiosa, lo es solo como "intención" de las expresiones sobre su fe de las tradiciones religiosas (103). Desde este punto de vista, la teología actúa entonces como ciencia de la religión (teología de la religión), cuyo método consiste en examinar las tradiciones religiosas basándose en el criterio de su propia concepción de la realidad divina (104); sin reducir, por esto, los enunciados sobre la fe de una tradición a antropología (105). La labor de la teología, concluye Pannenberg, consiste en analizar las tradiciones religiosas en general en sus tesis específicamente religiosas (106): teología de la historia de las religiones (107). Pannenberg lleva hasta el extremo su enfrentamiento contra el objetivo de la crítica de Feuerbach de hacer una antropología de la historia de las religiones (108). Como afirma Pannenberg: "El mundo de las religiones y la disposición religiosa del hombre en general documentada en ellas es el campo en el que debe situarse la teología para la confrontación con el ateísmo" (109). Según Pannenberg, es ese el lugar en el que se acoplan de nuevo historia y antropología, pues en la historia de las religiones, en tanto historia, se documenta la dimensión religiosa del ser humano, y no por pura deducción de una supuesta esencia abstracta del hombre. Es ahí mismo, en la historia de las religiones, donde se une -se media, podemos decir- la idea de Dios, como objeto de la teología, con la experiencia de la realidad, comprensible tan solo desde el hombre -concentración antropológica- y tomada, a la vez, en su totalidad para investigar su fundamentación última: Dios. Pannenberg retorna, pues, a la ciencia de la religión para corregir la interpretación de Feuerbach, haciendo ver que aquella no reduce el fenómeno religioso a un puro comportamiento humano sociológico o psicológico; todo lo contrario establece la especificidad de la experiencia religiosa, la cual estructura diversos elementos antropológicos en una unidad original: la experiencia "de" Dios. De ahí el carácter teológico de la ciencia de las religiones. Razón por la que esta "no debería limitarse a describir la experiencia religiosa humana, sus conexiones con las restantes experiencias y su institucionalización en el contexto de la vida social, sino que tendría que investigar también la realidad que se experimenta en la vida religiosa y en su historia" (110).

Según una opinión contraria, la sicología, la sociología, la historia de la religión y la fenomenología se ocuparán únicamente del aspecto humano de la religión, haciendo una suspensión de juicio respecto de la realidad del objeto de la experien-

(102) Cf. ibíd., 321-322.

(103) Cf. ibíd., 322.

(104) Cf.ibíd.

(105) Cf.ibíd.

(106) Cf. ibíd., 324

(107) Cf. ibíd., 326.

(108) Como afirma Feuerbach en el prólogo a la primera edición de 1841 de la Esencia del cristianismo: "La historia de la teología [de la religión] ha demostrado y confirmado a posteriori desde hace ya mucho tiempo, lo que en este escrito se ha demostrado, por así decir, a priori: $l a$ antropología es el misterio (Geheimnis) de la teología" (Das Wesen, 9-11).

(109) Reden von Gott, 35; cf. ibíd., 21.

(110) Wissenschaftstheorie, 365-366. 
cia religiosa. En otros términos, la ciencia de las religiones debe tomar una actitud neutra respecto de la realidad de Dios. La principal promotora de esa actitud ha sido precisamente la fenomenología de la religión. Así, por ejemplo, G. Van der Leeuw en su clásica obra Fenomenología de la religión afirma: "lo que la ciencia de la religión llama objeto de la religión, es para la religión misma, sujeto. El hombre religioso siempre ve aquello de que trata su religión como lo primario, lo causante. Solo para la reflexión se transforma en objeto de la experiencia observada. En la religión, Dios es el agente en la relación con el hombre; la ciencia puede solamente hablar de la actividad del hombre en relación con Dios, pero nada puede decir de la actividad de Dios" (111). El resultado de la postura fenomenológica es separar la teología de la ciencia de las religiones (Van der Leeuw), quedándose el científico más allá de una toma de postura -positiva o negativa- respecto al problema de la verdad de los asertos religiosos; es decir, más allá de un ilusionismo o de un realismo.

Para Pannenberg la pretendida neutralidad de la misma suspensión de juicio sobre la realidad del objeto de la religión es sospechosa; pues, según él, esa postura "se basa en un prejuicio a favor de una interpretación antropológica-inmanente de la religión" (112). La razón que da Pannenberg es que "cuanto más se consigue, aparentemente, concebir los fenómenos religiosos como formas expresivas de actitudes psíquicas y de situaciones sociales, tanto más superflua es, precisamente por eso, la hipótesis de una realidad trascendente como referencia de la experiencia religiosa" (113). La ciencia de las religiones excluye, pues, metodológicamente de su campo de investigación al objeto específico de la religión. Una mera sicología, fenomenología o sociología de la religión no considera de hecho su temática específica. Ahora bien, agrega Pannenberg, la pretensión de que investigaciones de este tipo son ciencia de la religión y de las religiones hay que calificarla de "problemática". Lo que debe esperarse de toda ciencia positiva es que investigue con imparcialidad su respectivo objeto y que no excluya metodológicamente aquellos rasgos que son constitutivos de su naturaleza específica, por lo que hay que tomar en serio la pretensión de verdad de las religiones (114). Este tomar en serio no tiene por qué significar -y para la investigación científica puede de hecho no significarlo- que se acepten tales pretensiones de verdad sin examinarlas. Una investigación científica puede admitir asertos solo en la medida en que los trata como problemáticos y procura examinar sus pretensiones. Tal examen tiene que referirse también a las implicaciones de los asertos que hay que examinar. Así, toda ciencia de las religiones es en última instancia teología, afirma Pannenberg, aunque la teología de las religiones tiene que ser una teología crítica. Una teología crítica de las religiones es teología "en cuanto examina las tradiciones y las formas de vida religiosa basándose en su temática específicamente religiosa, en la realidad divina que aparece en ellas, y no de otros puntos de vista cualquiera, como el sicológico o el sociológico" (115). Pero es

(111) Phänomenologie der Religion, Tübingen (2) 1956, 3.

(112) Wissenschaftstheorie, 366.

(113) Ibíd.

(114) Cf. las profundas e iluminadoras reflexiones a este respecto de R. Schaeffler, Erfahrung als Dialog mit der Wirklichkeit, Freiburg-München 1995. Últimamente ha desarrollado esta temática de forma muy sugerente F. von Kutschera, Vernunft und Glaube, Berlin-Nueva York 1991.

(115) Wissenschaftstheorie, 368. 
crítica en cuanto examina problemáticamente los asertos de las tradiciones religiosas, en el sentido de que considera a la historia de las religiones como "historia de la aparición, discutible (strittigen) en este proceso, de Dios" (116).

Como se habrá podido observar, una teología crítica de las religiones incluye una filosofía de la religión y una historia de las religiones, como disciplinas principales de la ciencia de las religiones. La función de la filosofía de la religión estriba en que "desarrolle el concepto universal de religión en general e inserte en este marco la idea de Dios como realidad que todo lo determina. Si se tiene presente la problemática que ha resultado del pensamiento moderno, tal filosofía de la religión requiere como base una antropología general" (117). Todo esto con un objetivo principal: "someter a examen tanto las formas religiosas fundamentales de representar el 'poder sagrado' de la realidad divina como asimismo su respectiva concepción del mundo y del hombre y también, en tercer lugar, las formas de relación religiosa, es decir, el culto" (118). Para esto, la filosofía de la religión tiene que basarse en los datos que le ofrecen la psicología de la religión, la sociología de la religión y la fenomenología de la religión. La tarea de la historia de las religiones no se limita solo a "organizar en una secuencia cronológica el material de información religiosa, sino sobre todo trazar los modelos del proceso evolutivo de las diversas religiones y, en fin, también de la historia de la religión en general" (119).

¿Cómo establece Pannenberg la relación entre teología de la religión, filosofía de la religión e historia de las religiones?

Primero habrá que precisar en qué sentido usa el término teología. Este lo toma como categoría que trasciende la diferencia entre filosofía de la religión e historia de las religiones (120). Pero no todo se limita aquí. Debido a que el concepto de teología tiene un origen filosófico, como lo ha analizado agudamente Pannenberg en su obra Una historia de la filosofía desde la historia de Dios (121), no se puede delimitar a priori de la filosofía: la filosofía griega es auténtica teología natural, porque está basada en la comprensión racional de la naturaleza misma de la realidad. La teología como la filosofía -y en este punto coincide con Heidegger- es una creación específica del espíritu griego. Y Aristóteles entiende por teología la rama fundamental de la ciencia filosófica que también llama "filosofía primera" o "ciencia de los primeros principios", la rama que más tarde recibe el nombre de "metafísica" entre sus seguidores. En este sentido es la teología la última y más alta meta de todo estudio filosófico del Ser. Se habla así de teología filosófica, la cual implica una determinada filosofía de la religión, tal como lo plantea Hegel en sus Lecciones sobre filosofía de la religión (122). Sin embargo, como señala Pannenberg, no toda filosofía de la religión ofrece también una teología de la religión. Muchas veces, la filosofía de la religión se limita a las características antropológicas de la vivencia

(116) Ibíd., 369, nota 687.

(117) Ibíd, 371.

(118) Ibíd.

(119) Ibíd., 371-372.

(120) Cf. Systematische Theologie 1, 11ss; Wissenschaftstheorie, 370-371, nota 689.

(121) Cf. Die Aufnahme, 296-346.

(122) Cf. Vorlesungen über die Philosophie der Religion. Einleitung, 31-92. 
religiosa, como ocurre también en las teorías transcendentales de un a priori religioso. En estos casos, subraya Pannenberg, queda incompleta la exposición filosófica del fenómeno religioso. En este punto es muy importante llamar la atención sobre la profunda influencia de las Lecciones sobre filosofía de la religión (El concepto de religión. Lección de 1821) de Hegel en Pannenberg (123). La Filosofía de la religión de Hegel presenta la historia de las religiones como la realización de su concepto universal, entendido en un sentido "teológico".

La postura que toma Pannenberg consiste por tanto en distinguir, por una parte, la exposición del concepto general de religión (124) en una filosofía de la religión, en cuyo marco es problemático el concepto de Dios, y, por otra, una teología de la historia de las religiones (incluyendo al cristianismo), que examina hasta qué punto se confirman y verifican, en la experiencia histórica de las religiones, los dioses que afirman las tradiciones. Según este punto de vista, la filosofía de la religión, la teología crítica de la religión y la historia de las religiones confluyen unitariamente dentro del marco general de la ciencia de las religiones.

Es por esta línea como Pannenberg intenta esclarecer la cientificidad de la teología en vistas a enfrentarse con la reducción feuerbachiana antes examinada por nosotros; es decir, para dar razón de su "objeto": Dios como realidad problemática. Por eso se plantea la cuestión sobre el carácter cognitivo de la proposición "Dios existe"; de si este enunciado afirma realmente algo sobre el hecho con pretensión de verdad.

\section{LA TEOLOGÍA COMO “CIENCIA” PROBLEMÁTICA}

Según el primer postulado ("postulado de proposiciones") del criterio de cientificidad de las proposiciones teológicas propuestas por Scholz, traído a colación por Pannenberg (125), en una ciencia, además de cuestiones y definiciones, solo pueden aparecer proposiciones, es decir, enunciados de los que se afirma que son verdaderos. Se trata de este caso de "proposiciones asertivas", en las que está incluido el principio de no-contradicción. Pero cabe afirmar algo más. Puesto que la reflexión teológica se concentra en las implicaciones cognitivas del lenguaje religioso, tendrá que encararse con el "postulado de la controlabilidad", propuesto también por Scholz, para comprobar la pretensión de verdad tanto del lenguaje religioso como de las mismas proposiciones teológicas (126). Para eso la reflexión teológica tiene que referirse primeramente a la unidad del campo temático de la teología ("postulado de coherencia", según el cual todas las proposiciones tienen que referirse a un campo unitario de objetos, como postula Scholz). Unidad que radica en la consideración de

(123) Cf. Systematische Theologie 1, 188ss.

(124) Pannenberg afirma que "un concepto general de religión es siempre abstracto, mientras que la realidad histórica de la religión solo se puede percibir en una descripción de esta historia y no en términos de conceptos generales" (Wissenschaftstheorie, 371, nota 689).

(125) Cf. ibíd., 270ss; Systematische Theologie 1,167ss.

(126) "Por lo que se refiere a la intención de afirmar algo como verdadero sobre la realidad divina y creada por Dios, entre lenguaje de la vida religiosa y el de la reflexión teológica, no existe una oposición de principio" (Wissenschaftstheorie, 331). 
todo lo real "sub ratione Dei" (127). El problema se centra, pues, en si cabe en esa unidad de campo "la posibilidad de distinguir a Dios, como objeto de la teología, de los asertos religiosos y teológicos sobre él" (128), teniendo en cuenta que solo así se podrá afrontar el problema de la "concentración antropológica" de la idea de Dios. Pannenberg afirma que "la única posibilidad de establecer con seguridad esta distinción es demostrar que la realidad de Dios, si es que la puede afirmar, se da implícitamente, como realidad que todo lo determina, en toda realidad finita, y particularmente en las estructuras de significado de todo hecho y de todo acontecimiento, que a su vez se tematizan en las experiencias que anticipan la totalidad de sentido de la realidad" (129). Puesto que esta formulación nos traza ya de antemano el camino para poder aclarar si es o no aplicable a la teología el "postulado de controlabilidad", habrá que analizarla con mayor profundidad.

En el texto anterior Pannenberg se ha referido a la relación dialéctica entre lo finito y lo infinito. La influencia de Hegel a la que ya hicimos referencia, es clara. Además, según Pannenberg, la vuelta a Hegel es necesaria para contrarrestar la crítica de Feuerbach (130). No es posible pensar lo finito sin lo infinito; que equivale a decir: filosóficamente no es posible pensar el hombre y la realidad -el mundosin poner, aunque solo sea implícitamente, a Dios como realidad que todo lo determina (131). Siguiendo a Hegel, Pannenberg acepta la comprensión de Dios como esencia (Wesen) del hombre, aclarando al mismo tiempo que Hegel no se estaba refiriendo a una "esencia inmanente a la humanidad", cual era el caso de Feuerbach, sino “a lo más allá de la manifestación (del fenómeno); en cuanto 'esencia' del hombre, Dios está más allá del hombre, determinando a este como determinación más allá de él" (132). Pannenberg trae a colación en este contexto la idea hegeliana, que el objetivo al que apunta la determinación del hombre consiste en pasar más allá de su finitud, sacrificarla y entregarse a lo infinito en fervor. "Pero desde sí mismo, desde su finitud, el hombre no podrá lograr la unidad con lo infinito más que tergiversándola: 'lo finito que se alza a lo infinito, es solamente identidad abstracta, en sí misma vacía, la forma suprema de la no-verdad, la mentira y el mal"" (133). Desde este punto de vista, la superación de la crítica de Feuerbach a la teología solo es posible retornando a la "dialéctica de lo infinito", mediante la cual podrá ser "recuperado" el "concepto" de Dios en tanto "saber" de Dios. En contra de Feuerbach, Pannenberg quiere hacer ver, recurriendo precisamente a la "dialéctica de lo infinito", que aun estando el hombre referido esencialmente a la infinitud, "nunca es ya en sí mismo infinito" (134). La metafísica moderna ha tenido conciencia de esta verdad al no poder pensar la subjetividad del hombre sin recurrir al presupuesto de

(127) Ibíd., 332-333; cf. Systematische Theologie 1, especialmente el primer capítulo.

(128) Wissenschaftstheorie, 333.

(129) Ibíd.

(130) Cf. Typen, 352-353

(131) Cf. Systematische Theologie 1, 188ss. 430, nota 129; Theologie und Philosophie, 257-293.

(132) Typen, 352-353, (con referencia a la Filosofía de la religión de Hegel).

(133) Ibíd. (en donde cita las Vorlesungen über die Philosophie der Religion [Die vollendete Religion] según la edición de la Jubiläumausgabe, vol. XV, 204).

(134) Ibíd., 353. 
Dios, como ha sido analizado magistralmente por W. Schulz (135), lo cual ha sido asumido consecuente y coherentemente por Pannenberg tras sus detallados análisis de este fenómeno (136). Por esto la idea de Dios es una "hipótesis necesaria" para poder comprender al hombre y a toda realidad. Esta hipótesis es necesaria porque es propio del ser humano "trascender" todo lo que existe, estar referido a una realidad infinita y totalizante (137): "quam omnes Deum nominant" (138). Pannenberg ha dedicado una parte significativa de una de sus obras más importantes, Antropología en perspectiva teológica a desarrollar este asunto (139). La pregunta fundamental que cabe hacer aquí según la lógica de la argumentación pannenbergiana se puede formular de la siguiente manera: ¿es aplicable a este aserto teológico un cierto "control" para que pueda ser considerado como "científico"? Si se tiene en cuenta que el libro Teoría de la ciencia y teología en el cual Pannenberg decide la respuesta a esta interrogante data de 1973, se puede hablar aquí de una decisión epistemológica decisiva (por ejemplo, en el carácter necesariamente hipotético del lenguaje asertórico) que marca la obra fundamental de este autor cuando desarrolle más adelante los temas de la dogmática en su gran Teología Sistemática y sobre todo el núcleo de esta, como él mismo lo expresa, el tratado de Dios/Trinidad. Al final de este artículo volveremos críticamente sobre este asunto.

El problema del control de los asertos teológicos es analizable desde una doble perspectiva. Lógicamente hablando el criterio negativo de un aserto consiste en que esté libre de contradicción. Es el requisito de la estructura lógica de un juicio: "De aquí se sigue el requisito ético-científico de que el teólogo cuando formula una proposición, tiene que asumir sus implicaciones lógicas y hacerlas explícitas, en interés de su verificabilidad, en todos los aspectos que sean relevantes para el respectivo tema" (140). Pero el control de los asertos se dirige sobre todo a la facticidad del hecho que se ha afirmado; en este caso: Dios como realidad que todo lo determina. Es ahora cuando se le complica el problema a la teología, porque los enunciados sobre Dios no son, evidentemente, controlables desde su objeto (141). Estas son las razones de la no controlabilidad de los enunciados teológicos: a) la realidad de Dios es discutible, problemática ("strittig") $(142)$; b) estaría en contradicción con el concepto de Dios - "realidad que todo lo determina"- que fuera un dato ("Gegebenheit") finito reproducible en cualquier momento (143). Dios es inobjetivable, infinito.

(135) Cf. Der Gott der neuzeitlichen Metaphysik, Pfullingen 1957.

(136) Theologie und Philosophie, especialmente los capítulos 6-11; Typen, 347-360; Wissenschaftstheorie, 308-309; Anthropologie und Gottesfrage, 9-28; art. Unendlichkeit, en: Historisches Wörterbuch der Philosophie, vol. 11, Basel 2001, 140-146; Fichte und die Methaphysik des Unendlichen, en: Beiträge 1, 32-44.

(137) Cf. Anthropologie in theologischer, sobre todo la primera parte; Weltoffenheit und Gottoffenheit, en: Was ist der Mensch? Die Anthropologie der Gegenwart im Lichte der Theologie, Göttingen (8) $1995,5-13$.

(138) Santo Tomás de Aquino, Sth. I, q. 2, a. 3; cf. Weltoffenheit und Gottoffenheit, 5-13.

(139) Cf. Weltoffenheit und Gottoffenheit, 5-13.

(140) Wissenschaftstheorie, 334; cf. I. Kant, Kritik der reinen Vernunft, en especial: Von dem obersten Grundsatze aller analytischen Urteile, 207ss (A 151ss).

(141) Cf. Wissenschaftstheorie, 335.

(142) Cf. ibíd.

(143) Cf.ibíd. 
De lo anterior pues se puede sacar la siguiente conclusión: los asertos teológicos sobre la realidad de Dios - "Dios existe"- no son controlables directamente, como lo puede ser cualquier objeto finito a disposición, a mano del observador. ¿Se da, no obstante, algún otro tipo de control de los asertos teológicos? También se pueden probar unos asertos por sus implicaciones (144) . En este caso, señala Pannenberg en una toma de postura formal programática decisiva para todo su quehacer teológico: "las afirmaciones sobre la realidad divina y sobre la acción divina se pueden controlar por sus implicaciones para comprender la realidad finita, en la medida en que el objeto de tales afirmaciones sea realmente Dios como realidad que todo lo determina" (145). Se trata entonces de un control "indirecto", en el cual Pannenberg ve la clave para demostrar la "racionalidad científica de la teología".

Pannenberg considera a los enunciados teológicos como "hipótesis", los cuales, lo mismo que las proposiciones científicas, "se dan en el marco de unos contextos teóricos y solo se pueden controlar considerando su función en el contexto de sus respectivos sistemas teóricos" (146); de aquí el requisito de la teología de construir unos "modelos teóricos" (147). El contexto teórico de la teología es la consideración de la realidad en su conjunto (totalidad) tal como sucede en la conciencia religiosa. Ahora bien -y esto es importante, pues aparece un concepto clave y muy discutido de Pannenberg- "en cuanto tales experiencias se basan en una anticipación de la totalidad de lo real, aún inacabada en el proceso de la realidad, toda experiencia de sentido es hipotética en el sentido del principio de Popper de la "prueba y el desacierto' (trial and error)" (148).

Los enunciados teológicos, como los filosóficos, son hipótesis sobre la totalidad del sentido de la experiencia; pero hipótesis construidas, en primer lugar, desde el punto de vista de la realidad que en última instancia determina todo lo dado en su totalidad aún inacabada, y, en segundo lugar, desde el aspecto de cómo se ha manifestado esta realidad divina en la conciencia religiosa (149). Cabe ver aquí por tanto un doble aspecto de los enunciados teológicos: a) como hipótesis históricas y hermenéuticas; en este sentido, deben satisfacer los criterios de las hipótesis históricas y hermenéuticas; $b$ ) la afirmación de Dios como realidad que todo lo determina, teniendo en cuenta que "la presencia de esta realidad en un fenómeno histórico solo puede ser objeto de una investigación reflexionando sobre la totalidad de sentido implícita en él" (150) y que incluye no solo el pasado, sino también el presente y el futuro.

(144) Cf.ibíd.

(145) Ibíd.

(146) Ibíd.

(147) Ibíd.

(148) Ibíd., 336. Popper está muy presente en el pensamiento de Pannenberg. Para el concepto fundamental de la teología pannenbergiana de "anticipación" cf. su artículo clave, Begriff und Antizipation, en: Metaphysik und Gottesgedanke, Göttingen 1988, 66-79; ver igualmente Systematische Theologie 1, 249ss. Para la discusión sobre la forma cómo Pannenberg utiliza este término cf. L. Kugelmann, Antizipation. Eine begriffsgeschichtliche Untersuchung, Göttingen 1986, 52ss. 251ss; M. Schulz, Sein, 431-444. Para la relación crítica Popper-Pannenberg, ver I. Orellana, La cuestión del estatuto científico de la teología: Popper-Pannenberg, Salamanticensis 45 (1999), 443-474.

(149) Cf. Wissenschaftstheorie, 344.

(150) Ibíd., 341. 
Pannenberg, basándose en la distinción -inspirado en parte en la hermenéutica de su maestro Gadamer (151) - entre el "horizonte de sentido" del fenómeno histórico y el "juicio actual" sobre el fenómeno (152), afirma que "en la interpretación teológica lo que importa no es primeramente la facticidad histórica de un fenómeno pasado, sino presupuesta esta, poner de manifiesto en aquel fenómeno la realidad que todo lo determina, que también se revela como tal en la experiencia actual" (153). En este sentido "la construcción de conceptos y de teorías en teología es autónoma en relación con los datos históricos en que se basan, porque su verdadero objeto no es su historicidad, sino el contenido que se ofrece en ella, es decir, la realidad de Dios que todo lo determina" (154). Desde este punto de vista, la problemática de la teología coincide con el problema filosófico de la realidad en general y tiene que regirse por los criterios de control por lo que se juzgan los enunciados filosóficos. Ahora bien, dada la naturaleza de los enunciados teológicos -se refiere a la realidad en su conjunto, es decir, a la totalidad del proceso temporal histórico- su control no puede ser concluyente para quien está en medio del proceso todavía abierto (155). A partir de una idea central del planteo de Dilthey que en la obra de Pannenberg cobrará un carácter "hermenéutico" significativo, este último afirma que "solo el fin de la historia puede proporcionarnos la decisión definitiva sobre todos los asertos que se refieren a la realidad de su conjunto y, por tanto, también a la realidad de Dios y al destino del hombre" (156). Las últimas citas de Pannenberg nos muestran el carácter escatológico del concepto de Dios, mediado siempre por la historia de las religiones, por lo que se puede concluir que la hipótesis de Dios, como realidad que todo lo determina, está confirmada, aunque no concluyentemente, por la historia de la experiencia religiosa, comprendida esta como la historia de la automanifestación de Dios co-dada (mitgegeben) indirectamente en toda experiencia de sentido (157). Razón por la que la anticipación de totalidad hace que las aserciones sobre Dios tengan un carácter hipotético e histórico, hasta el punto que la nueva experiencia histórica de la realidad puede provocar y exigir una revisión del proyecto de totalidad de sentido -como está pasando en el proceso de secularización (158)-, pues no solo la experiencia singular es comprendida dentro del horizonte de

(151) Cf. Hermeneutik und Universalgeschichte, en: Grundfragen 1, 91-122.

(152) Cf. Wissenschaftstheorie, 341-342.

(153) Ibíd., 341-342.

(154) Ibíd., 342.

(155) Cf. ibíd., 346-347; Systematische Theologie, vol. 3, Göttingen 1993, 600, nota 95; Ch. Mostert God and the Future. Wolfhart Pannenberg's Eschatological Doctrine of God, Londres-Nueva York 2002; íd., From Eschatology to Trinity. Pannenberg's Doctrine of God, Pacifica 10 (1997), 70-83.

(156) Wissenschaftstheorie, 346-347; cf. Grundfragen 1, Heilsgeschehen und Geschichte, 22-78; Eschatologie und Sinnerfahrung, en: Grundfragen systematische Theologie. Gesammelte Aufsätze, vol. 2, Göttingen 1980, 66-79; Die Bedeutung der Kategorie "Teil" und "Ganzes", 85-100; Sinnerfahrung, Religion und Gottesfrage, 101-113. Un buen resumen para ubicar toda esta problemática en la obra de Pannenberg lo ofrece, P. de Vitiis, Il problema della rivelazione nel pensiero di W. Pannenberg, Archivo di filosofia 62 (1994), 875-887.

(157) Cf. la sintética presentación que hace de esta temática al interior de la arquitectura del primer volumen de la Teología Sistemática, J.A. Martínez-Camino, Aufhebung. Zur Architektur des ersten Bandes der 'Systematischen Theologie' Wolfhart Pannenbergs, Kerygma und Dogma 45 (1999), 91-101.

(158) Cf. los agudos análisis de A. Torres Queiruga, en especial de los planteos ya clásicos P.L. Berger y Th. Luckmann (La constitución moderna de la razón religiosa, Estella 1992, 63ss). 
la totalidad de sentido anticipada, sino que también la anticipación de la totalidad de sentido está controlada por cada una de las experiencias singulares y fácticas de la realidad (159). Pero al estar situado Dios en el plano de la totalidad, y esta es tal solo desde el final de todo el proceso histórico, aquel no puede ser nunca un ente más entre los entes finitos y dados, sino "Dios del futuro". Por esto el lenguaje teológico es un lenguaje escatológico marcado intrínsecamente por la mediación histórica; de aquí que el momento de la anticipación implica siempre el momento hipotético, "un momento de proyección subjetiva, que hay que confirmar o rechazar en el proceso de la experiencia" (160). Tal es el fundamento de la propia decisión de la teología de hablar de Dios como "problema". El "sub ratione Dei" de la teología no es un "presupuesto dogmático" (161), sino algo que debe "resultar" convirtiéndose entonces en un "en vistas a Dios" o en "Dios como horizonte".

Pero se interroga Pannenberg (162), de si no esté en nuestros días Dios bajo la sospecha de que no es más que una idea de la fe, una representación religiosa, producto de un período de la historia de la humanidad ya superado, en una línea que va de, entre otros trazados posibles, de Lessing a Feuerbach desembocando en los así llamados por Ricoeur "maestros de la sospecha". Si así fuera, la teología tendría que replantearse el concepto de Dios, para investigar qué es lo que propiamente se indica en él, pero que solo inadecuadamente se expresa. En este caso, posiblemente tendría que haber cambiado también con el tiempo el nombre de "teología" por otro nombre que correspondiera mejor a la realidad que está detrás de la idea de Dios. Pero incluso en los círculos y ambientes de crítica de la religión, donde se piensa que el problema de Dios ha quedado definitivamente resuelto y sellado, no existe un acuerdo sobre lo que está detrás de la idea de Dios. Y tampoco la crítica de la idea de Dios, en cualquiera de las variantes de la teoría de la proyección, puede presentarse hoy como tan críticamente cierta que ya no necesita una crítica y que su planteamiento de principio puede valer a priori como regresión a una fase de reflexión ya superada. Más bien hay que pensar que todo lo que se ocupa de la herencia de la tradición teológica tiene hoy una conciencia clara del problema de saber, al menos, que la problemática -histórico-teológica, como la entiende y analiza Pannenberg- de Dios está abierta e incompleta. La teología no puede olvidar jamás, insiste Pannenberg, su propia condición esencial de ser "teología problemática".

\section{LA CUESTIÓN DE DIOS Y LA ESTRUCTURA TEOLÓGICA DE LA CONSTITUCIÓN DEL HOMBRE. HACIA UNA TEOLOGÍA ESCATOLÓGICA}

La teología tiene que enfrentarse con el siguiente problema fundamental: ¿es todavía hoy necesaria la hipótesis "Dios" para la comprensión actual de la realidad y del hombre, cuando dicha comprensión está determinada por la racionalidad científi-

(159) Cf. Wissenschaftstheorie 312-313; Hermeneutik und Universalgeschichte, 121.

(160) Wissenschaftstheorie, 312.

(161) Ibíd., 301.

(162) Cf. ibíd., 300-301. 
ca y técnica? ¿No es verdad que incluso "para el pensamiento filosófico la pregunta sobre Dios como fundamento supremo de todo lo existente se ha hecho tan radicalmente problemática en los últimos 150 años que representa ya una sensación el que un filósofo quiera hoy abordar de nuevo la antigua temática de la doctrina filosófica de Dios?" (163). La pregunta sobre Dios debe partir, pues, del ateísmo moderno, radicado en la experiencia fundamental de que "Dios ha muerto" y cuya expresión específica se encuentra en el ateísmo antropológico. Con respecto a esto Pannenberg señala: "La forma de vivir y de pensar sin Dios, el ateísmo secular, es el terreno aceptado evidente, en el que hoy día se mueve la pregunta misma sobre Dios" (164). Ante el reto del ateísmo moderno ya no se puede hablar de Dios -en reacción al principio fundamental del teocentrismo barthiano, amplificado luego por E. Schaeder, que se expresa por ejemplo en la obertura teológica de su Carta a los Romanos, de que a Dios no se lo conoce sino por la revelación, lo que condiciona la correspondencia entre pregunta humana y respuesta divina- en un lenguaje -unilateralmente- "teocéntrico".

Pannenberg es plenamente consciente de que la decisión última sobre la posibilidad de una idea y lenguaje sobre Dios está radicada fundamentalmente en la comprensión del hombre $\mathrm{y}$, por consiguiente, que a Dios solo se le puede conocer -"teología"- mediante el hombre -"antropología"-. De aquí que replantee la pregunta sobre Dios tomando como punto de partida la "concentración antropológica" del lenguaje teológico. La posibilidad de una idea de Dios debe decidirse actualmente en la comprensión del hombre. Según Pannenberg los temas antropológicos que muestran la dimensión teológica de la antropología son: el carácter cuestionador de la existencia humana (Fraglichkeit, Fragcharakter des menschlichen Daseins) y la apertura al mundo (Weltoffenheit) como estructura propia del ser del hombre (165).

El carácter interrogador (interrogabilidad) del hombre significa, en sentido positivo, que este es un ser que preguntando siempre va más allá de sí mismo y de todo lo dado fácticamente. La estructura fundamental del ser humano se la determina, pues, como pregunta, por la que se muestra tanto su carácter de apertura hacia el mundo como el proyecto anticipatorio de respuesta a la pregunta (166). Pero se cuestiona Pannenberg, “¿qué tiene que ver con Dios esta pregunta? ¿No podría quizás la naturaleza interrogadora del hombre estar constituida de forma tal que no apunte a ninguna clase de respuesta última?" (167). No se puede olvidar la moderna experiencia "nihilista", según la cual ya no cabe ninguna respuesta insobrepasable.

(163) Die Frage, 361.

(164) Ibíd., 362.

(165) Cf. Weltoffenheit und Gottoffenheit, 5-13, donde se ven las influencias de Scheler, Gehlen y Plessner. Ver también la exposición detallada y pormenorizada de todos estos temas en, Anthropologie in theologischer, sobre todos los capítulos 1-2; para Heidegger, ver ibíd., capítulos 5-6. Un buen resumen de las influencias de estos pensadores en la antropología pannenbergiana y la relación de esta con su teología lo ofrece, P. de Vitiis. Antropologia e superamento del soggeto in W. Pannenberg, Archivo de filosofía 54 (1986), 435-454. Sobre aquella "estructura propia del hombre" cf. M. Heidegger, Die Grundbegriffe der Metaphysik. Welt-Endlichkeit-Einsamkeit (Gesamtausgabe, vol. 29/30), Frankfurt a.M. (2) 1992.

(166) Cf. Die Frage, 372-373; Weltoffenheit und Gottoffenheit, 5-13.

(167) Die Frage, 373. 
Todo está, incluido el hombre, bajo el signo de la carencia de fundamento (168). Desde esta óptica, la pregunta sobre Dios conduce a "nada". En la interrogabilidad del nihilismo no se trata, pues, de un interrogar que apunta a una respuesta insobrepasable, sino de un poner en cuestión a todo, incluida la misma respuesta. La pregunta es un simple juego que construye y destruye a la vez.

Pannenberg entra en esta temática en su ensayo La pregunta por Dios (169) en un interesante diálogo crítico con $\mathrm{W}$. Weischedel. Pannenberg muestra cómo este filósofo ha tomado la carencia total de fundamento como punto de partida de sus consideraciones sobre la posibilidad de una "teología filosófica en las sombras del nihilismo". La tesis de la que parte Weischedel es que a esa total interrogabilidad debe ponérsela en cuestión, queriendo hacer ver que también ella necesita de una fundamentación: el "porqué" de la pregunta. Para Weischedel, cuando la autocerteza del interrogar radical haya sido puesta en cuestión buscando al mismo tiempo el fundamento de tal interrogar en totalidad, se habrá dado un paso más allá del nihilismo, siendo de nuevo pensable Dios. Pannenberg impugna la legitimidad de este paso: "El tránsito de total interrogabilidad nihilista a la idea de que el interrogar hace referencia a un 'desde dónde', tiene una estructura distinta a la del interrogar nihilista mismo, y no puede por tanto hacérselo valer exclusivamente como consecuencia del interrogar nihilista. La actitud nihilista fundamental de poner en cuestión todas las certezas afirmadas tiene el carácter de un puro distanciamiento, de una negación vacía. En cambio, la pregunta sobre el fundamento de algo, sobre el desdedónde (Vonwoher) de algo, apunta, en cuanto pregunta 'sobre algo', a una posible respuesta" (170). La cuestión gira en torno a dos tipos de pregunta que Weischedel confunde, a juicio de Pannenberg, pues el interrogar filosófico tan pronto lo entiende como un preguntar que tiende a una posible respuesta como un simple poner en cuestión las certezas afirmadas. Por una parte, si la pregunta filosófica no apuntara a una posible respuesta, no sería un "interrogador serio" señala Weischedel; es más, para Weischedel, el juego escéptico de un "arte por el arte" no es filosofía. Pero por otra parte, el filósofo, movido siempre por una total radicalidad, tiene que ir poniendo incesantemente en cuestión cada respuesta lograda, retirándole una y otra vez todas las "esclerotizaciones de la idea hacia un nuevo interrogar". Ahora bien, el que cada respuesta lograda pueda ser superada nuevamente, no significa que a la pregunta filosófica se la prive de intención hacia una respuesta última. De aquí que, según Weischedel, cuando se diga que la pregunta filosófica "no puede detenerse en su radicalidad hasta haber hecho cuestionable incluso aquello que es para ella último -a saber, la idea de Dios como primer fundamento u origen"-, dicha pregunta -el

(168) Cf. F. Nietzsche, Der Antichrist. Ecce homo, et al., G. Colli-M. Montinari (eds.), KSA 6, München 1988; id., Nachgelassene Fragmente. Anfang 1888 bis Anfang Januar 1889, G. Colli - M. Montinari (eds.), Achte Abteilung-Dritter Band, Berlin-Nueva York 1972, 260ss; M. Heidegger, Nietzsche: Der Wille zur Macht als Kunst (Gesamtausgabe, vol. 43), Frankfurt a. M. 1985; íd., Nietzsches metaphysische Grundstellung im abendländischen Denken: Die Ewige Wiederkehr des Gleichen (Gesamtausgabe, vol. 44), Frankfurt a. M. 1986; id., Nietzsches Wort "Gott ist Tod", en: Holzwege (Gesamtausgabe, vol. 5), Frankfurt a. M. (2) 2003, 205-263.

(169) Para la discusión con Weischedel, cf. Die Frage, en diálogo con el ensayo este filósofo, Die philosophische Theologie im Schatten des Nihilismus, Evangelische Theologie 22 (1962), 233249, al que se remiten las citas que siguen; ver también Systematische Theologie 1, 130-131.

(170) Die Frage, 373-374. 
poner en cuestión- equivaldría entonces a la duda vacía, a la que el mismo Weischedel le ha denegado de antemano la dignidad de lo filosófico. La pregunta originaria está siempre a la expectativa de una respuesta última. Tanto es así que la razón del ser del interrogar radica en la posibilidad de respuesta. Pero Weischedel afirma algo mucho más fundamental: solo en cuanto respuesta que sale al paso de la pregunta existencial del hombre, será Dios simultáneamente aquel de quien procede el "reto lanzado a la interrogación"; será, por tanto, el "origen de la libertad humana". Pero se cuestiona Pannenberg: ¿tiene esto validez también respecto a la estructura interrogadora de la existencia humana?, ¿presupone la apertura característica del comportamiento humano un fundamento sustentador de ese estilo -a saber, diferente de todo el ámbito de lo factual (o sea el mundo)-, debido a que sobre ese fundamento es precisamente sobre lo que el hombre interroga en su apertura, cuando pregunta más allá de todo lo factual (Vorfindlichem)? (171) Y se interroga una vez más nuestro autor: ¿u ocurre, por el contrario, que esa apertura es solamente expresión de la capacidad autocreadora del hombre mismo como "ser actuante" en el sentido de la antropología filosófica de base biológica como la representada por A. Gehlen y de acuerdo con la filosofía nietzscheana de la voluntad? Pannenberg ve aquí el problema central de la apertura al mundo o autotrascendencia del hombre (172).

Cabe distinguir un doble movimiento de esta apertura al mundo: la situación de "indigencia" y su fundamentación en una "totalidad"; la existencia del hombre deberá presuponer, pues, al menos la posibilidad de esa totalidad. Ahora bien, en la medida en que el fundamento que la posibilita, subraya Pannenberg, no puede encontrarse ni en el hombre mismo ni en el mundo factual (por su condición de finitud, de "recortado" (173)), siempre habrá de encontrarse previamente presupuesto en la existencia del hombre, "en cuanto realidad que sustenta dicha existencia y su mundo" (174). Aquí podemos ver la referencialidad (Angewiesenheit) del hombre a un fundamento. Pero es precisamente ahora cuando la cuestión que estamos tratando se pone más delicada, grave, pues a propósito de esa referencialidad del hombre a un fundamento surge la pregunta decisiva: ¿deberá ser definida como referencialidad a Dios, como pregunta sobre Dios? (175).

A la interrogante con que concluimos el párrafo anterior responde Pannenberg de la siguiente manera: "La pregunta existencial del hombre no apunta directamente a una persona, y por tanto tampoco a Dios, sino que de primera intención solo evidencia al hombre como referido al hecho de encontrarse con un fundamento que lo sustenta, que lo sustenta tanto a él, es decir, a la existencia del hombre como trascendencia hacia lo abierto (ins Offene), cuanto asimismo al mundo, es decir, al conjunto de toda la realidad factual" (176). Y añade el autor: "Sin embargo, claro está, esa pregunta da siempre un anteproyecto de la respuesta posible (Vorentwurf

(171) Cf. ibíd., 375-376.

(172) Para desarrollos más pormenorizados de esta temática, además del ensayo Die Frage, 361-386, cf. Anthropologie in theologischer, sobre todo el capítulo segundo, 40-76; Systematische Theologie 1, 167ss.

(173) Cf. Systematische Theologie 1, 182, en referencia a Schleiermacher.

(174) Die Frage, 377.

(175) Cf. ibíd., 377

(176) Ibíd., 377-378. 
möglicher Antwort). Por eso siempre ha ido intentándose, una y otra vez arrancar la respuesta a la pregunta existencial del hombre, o a la interrogabilidad (Fraglichkeit), por ella descubierta, del mundo de lo finito" (177). Desde este punto de vista cabe replantear la intención última de las pretendidas pruebas de la existencia de Dios (178). En esto Pannenberg sigue a Tillich (179), quien dice que los argumentos a favor de la existencia de Dios ni son argumentos ni constituyen la prueba de la existencia de Dios. Son expresiones de la cuestión de Dios, que está implícita en la finitud humana. "Esta cuestión es la verdad de tales argumentos". Todo este planteamiento que Pannenberg hace suyo está condicionado por el pensamiento dialéctico de Hegel (180), por el cual las pruebas de Dios son la "elevación” a Dios, en el sentido de un pasar de lo finito a lo infinito (181).

En un importante texto del primer volumen de su Teología Sistemática expresa Pannenberg lo siguiente a propósito de la renovación de las pruebas de la existencia de Dios llevada a cabo por Hegel (con referencia a la Enciclopedia de las ciencias filosóficas [1817] § 50); estas eran para él: "una expresión de cómo el espíritu humano se eleva por encima de lo dado a los sentidos y sobre todo lo finito en general hasta la idea de lo infinito y hasta la generalidad del concepto" (182). Y agrega Pannenberg que Hegel, como Kant, entendió que la idea de Dios es una idea necesaria para la razón (Vernunft), pero a diferencia del filósofo de Könisberg, Hegel no contemplaba a la razón como algo meramente subjetivo, sino que pensaba que la separación entre sujeto y ser en sí es una forma de pensamiento subjetiva, del entendimiento (Verstandes), que es superada por el conocimiento racional (Vernun fterkenntnis) (183). Con todo, agrega Pannenberg, también Hegel aplicó su crítica a la forma que adoptan las pruebas de la existencia de Dios. Porque tratan las cosas finitas como firme punto de partida, al tiempo que hacen aparecer la existencia de Dios como una consecuencia dependiente de este punto de partida. Según este filósofo, la verdad es lo contrario: "No se da la necesidad absoluta porque exista lo contingente, sino más bien porque esto es un no-ser, solo

(177) Ibíd., 378.

(178) Pannenberg expone esta temática -que en su obra juega un rol muy importante- de forma amplia y detallada en Systematische Theologie 1, 108-194. 380-390; es interesante el análisis cronológico que realiza el autor de esta problemática en Theologie und Philosophie, en los capítulos 7-10. Para esta problemática en su conjunto resultan muy iluminadoras las breves reflexiones de J. Clayton, art. Gottesbeweise (II-III), en: Theologische Realenzyklopädie, vol. XIII, Berlín-Nueva York 1984, 724-784. Para una visión amplia cf. W. Röd, Der Gott der reinen Vernunft, München 1992.

(179) Las citas de Tillich que siguen hacen referencia al primer volumen de su Teología Sistemática citado por Pannenberg en Die Frage, 378-379, ver nota 36.

(180) Aquí también juega un rol decisivo la interpretación, en esta línea de la "dialéctica del infinito", que realiza Pannenberg de la III Meditación de Descartes; cf. Systematische Theologie 1, 119ss; Theologie und Philosophie, 142-157; Religion und Metaphysik, 52-54; Offenbarung als Kategorie, 238-245. Es importante señalar aquí, pues a veces se pasa de largo en este punto, que para Pannenberg no se puede afirmar que con la idea de lo absolutamente perfecto se haya alcanzado ya la idea de Dios (cf. Das Problem des Absoluten, en: Metaphysik und Gottesgedanke, 24-25).

(181) Cf. las profundas reflexiones que ofrece P. Trawny con respecto a la temática de las pruebas de la existencia de Dios en Hegel en, Die Zeit der Dreieinigkeit. Untersuchungen zur Trinität bei Hegel und Schelling, Würzburg 2002, 31-40.

(182) Systematische Theologie 1, 103.

(183) Cf. ibíd., 103. 
apariencia, porque su ser no es verdadera realidad; es aquella la que es su ser y su verdad" (184). De esta forma, la elevación sobre lo infinito, señala Pannenberg, que se realiza en las pruebas de la existencia de Dios, significa, en oposición a la forma lógica de su argumentación, que lo finito no posee un ser últimamente autónomo. Según Hegel, las pruebas de la existencia de Dios, en cuanto expresión de cómo el espíritu humano se eleva más allá de lo finito hasta la idea de lo infinito, están en correspondencia con la vida propia de la religión. Son como un precipitado conceptual de la elevación religiosa a la participación de la realidad divina, pero expresada en la forma propia del entendimiento (Verstandesdenken). De ahí que Hegel, apunta Pannenberg, haya intentado también desarrollar una correspondencia entre los diversos tipos de pruebas de la existencia de Dios y los diversos grados de desarrollo de la religión: la prueba cosmológica se correspondería con la religión natural, la prueba fisicoteológica, con las religiones de la subjetividad espiritual y la prueba ontológica, con la religión de revelación, como expresión de la autorrevelación de Dios. De esta manera, señala Pannenberg, además de poner de manifiesto que la teología filosófica depende de las diversas formas históricas concretas de religión, Hegel anticipaba los resultados de los análisis más recientes sobre la historia de las pruebas de la existencia de Dios que nos muestra cómo la forma que estas adoptan en cada caso está en relación con la comprensión de la divinidad de la respectiva tradición religiosa y cómo experimentan hondos cambios cuando se modifica el contexto tradicional pasando a otras culturas religiosas.

La forma concreta de llevar a cabo la elevación hacia lo infinito, hacia Dios, es la pregunta sobre Dios, y su formulación teórica la constituyen las pruebas de la existencia de Dios: "dichas pruebas siguen conservando su significado en cuanto elaboración de la interrogabilidad de lo finito. Pero no dan la respuesta a esta pregunta" (185). Por esta razón, insiste Pannenberg, la teología filosófica debe tener siempre un carácter "cuestionador", no dogmático. En otras palabras, debe ser siempre "teología problemática" (186). Dios es, por consiguiente, objeto de la teología solo como problema, no como respuesta. La pregunta, en tanto que tal, aun anticipando una respuesta posible, permanece siempre, a juicio de Pannenberg "irresuelta, inconclusa, abierta a la realidad interrogadora, como instancia que se levanta frente a ella y es distinta de ella" (187). El logos de la teología no tiene, pues, un carácter "fundamentador" y, por consiguiente, "dogmático", sino crítico y cuestionador, lo cual la acerca a la visión que tiene Heidegger de la filosofía, en cuanto el preguntar es la "piedad" del pensar, y por ello aquí es posible -salvando las distancias del difícilmente homologable mundo propio heideggeriano- concebir a ese logos como espacio de libertad. La consecuencia que saca de esto Pannenberg es que "el modo como hay que concebir a Dios como objeto de la teología corresponde, por tanto, exactamente a la posición problemática que tiene la idea de Dios en nuestra experiencia" (188).

(184) Vorlesungen über die Beweise vom Dasein Gottes, (ed. Lasson), Hamburgo 1966, 103.

(185) Die Frage, 378.

(186) Cf. Wissenschaftstheorie, 368-369, ver nota 687.

(187) Die Frage, 379; cf. también Wissenschaftstheorie, 347-348; Systematische Theologie 1, 131ss.

(188) Wissenschaftstheorie, 302. 
Ahora bien, si lo que se muestra en las pruebas de la existencia de Dios es la necesidad de preguntar más allá del mundo y del hombre como ser finito, buscando un fundamento de su ser y del sentido de su existencia, cabe entonces plantearse las siguientes cuestiones: ¿cuál es el origen de los proyectos de respuesta implicados en el interrogar humano? ¿Son meras creaciones o imaginaciones del hombre? Más en concreto, ¿la pregunta sobre Dios se refiere a algo "real" o más bien está marcada intrínsecamente por una pura ilusión? Ante estas desafiantes interrogantes responde Pannenberg afirmando: "cuando la existencia del hombre se mueve por la pregunta sobre su disposición y planificaciones, está ya siendo promovida por la realidad hacia la que ese interrogar se dirige. El hombre, entonces, está ya experimentando la realidad (Wirklichkeit) por la que se interesa en su pregunta, está experimentando la profundidad no objetiva de aquella realidad, factual, realidad que sustenta también su propia vida" (189). De donde se deduce entonces según Pannenberg que "todo el contenido de la respuesta está ya anticipada en la pregunta" (190), si bien "toda proyección de posibles respuestas siempre se encuentra mediatizada (vermittelt) por una experiencia de aquella realidad sobre la cual versa la pregunta" (191). Aplicado esto último a la pregunta sobre Dios en la teología de Pannenberg significa la implicación de Dios en la respuesta y el hecho consecuente que Dios, como respuesta, no solo está implicado, sino también anticipado por la pregunta.

\section{La implicación de Dios en la pregunta teológica}

Dios, como respuesta, está implicado en la pregunta teológica; de aquí la reivindicación por parte de Pannenberg del argumento ontológico (192): "la idea de Dios, por su mismo concepto, es decir, como realidad que todo lo determina, hay que demostrarlo partiendo de la realidad del mundo y del hombre" (193). Pero "la idea de Dios se mide y examina en sus propias implicaciones" (194), no por algo exterior a ella; de no ser así, el proceso probatorio, en tanto elevación -tránsito- de lo finito a lo infinito, sería imposible. Expresado de otra manera, la idea de Dios, en tanto pregunta sobre Dios, implica previamente - a priori- la conciencia de Dios como "automanifestación" (195). Este método es "adecuado a la forma de la prueba ontológica de la existencia de Dios, es decir, es autodemostración de Dios (Selbstbeweis Gottes)" (196). Y en este sentido, subraya Pannenberg, es válida la tesis barthiana según la cual la interrogabilidad del hombre únicamente es puesta al

(189) Die Frage, 379-380; cf. Sinnerfahrung, 101-113.

(190) Die Frage, 379.

(191) Ibíd., 380.

(192) Para analizar la recepción del "argumento ontológico" de Anselmo en la obra de Pannenberg cf. Nutzen der Eschatologie für die christliche Theologie, Kerygma und Dogma 25 (1979), 89; Systematische Theologie 1, 61ss. 95ss.

(193) Wissenschaftstheorie, 302.

(194) Ibíd.

(195) Cf. Wissenschaftstheorie, 318ss. Aquí se puede ver una fuerte influencia de Hegel en Pannenberg, sobre todo de las Lecciones sobre filosofía de la religión (El concepto de religión) y de las Lecciones sobre las pruebas de la existencia de Dios.

(196) Wissenschaftstheorie, 302. 
descubierto desde la respuesta (197). El preguntar es así pro-vocado. Claro está que la prueba ontológica no es concluyente, puesto que su resultado está referido a la realidad siempre abierta y, por consiguiente, aún no acabada. De aquí que Dios siga siendo siempre una "hipótesis necesaria" dentro del proceso mismo de la autocomprensión del hombre (198). En este sentido, nosotros pensamos que Pannenberg, sin renunciar a la iniciativa gratuita divina en la creación (ex nihilo) y revelación, realiza la mediación necesaria con la razón moderna en el terreno de esta: la antropologización de la idea de Dios. En este carácter de necesidad radica precisamente la no reductibilidad de la idea de Dios a otra instancia externa a ella. Nosotros creemos hallar aquí uno de los significados más importantes de la "mediación" hegeliana de lo infinito en lo finito, y que Pannenberg asume para confrontar la crítica ("sospecha") de Feuerbach a la teología. El contrapeso de la crítica de Feuerbach es la "dialéctica de lo infinito" en tanto dialéctica de la pregunta por Dios; solo esta nos hace ver el carácter no resuelto, abierto de la hipótesis de Dios: "el modo como hay que concebir a Dios como objeto de la teología corresponde, por tanto, exactamente a la posición problemática que tiene la idea de Dios en nuestra experiencia" (199). Esto último no significa para Pannenberg de ninguna forma abdicar al carácter crítico de la teología. Esta, como esfuerzo finito del conocimiento de Dios que es, "está expuesta constantemente a la posibilidad de que su objeto, en el curso mismo de su explicación, podría quedar reducido a otro objeto distinto y la teología, en consecuencia, quedar absorbida en otra disciplina" (200). En otros términos, la teología nunca puede perder de vista la posibilidad de que su objeto (Gegenstand) -Dios- fuera el resultado de una mera ilusión proyectada, sin que le correspondiera realidad alguna. En este sentido, hay que reconocer, como Pannenberg lo expresa no sin cierta ironía, que Feuerbach ha sido el "gran maestro" de la teología al hacerle tomar conciencia de que Dios es su objeto "solo como problema, no como dato cierto" (201).

\section{Dios, como respuesta está anticipado por la pregunta}

Dios, como respuesta, no solo está implicado, sino también anticipado por la pregunta. Aquí podemos distinguir dos aspectos: a) el carácter escatológico del concepto de Dios (202) y b) la conexión, desde el punto de vista de la teología filosófica problemática, del argumento ontológico con el argumento teológico o del sentido escatológico. Si como ya hemos señalado, la interrogabilidad del hombre sobre la realidad de Dios solo puede ser puesta al descubierto por la respuesta divina, no obstante, por su carácter hipotético-problemático, es una respuesta que "no da conclusión a la pregunta" (203), sino que siempre "va por delante" de esta

(197) Cf. Systematische Theologie 1, 129-132; ver los textos de K. Barth, KD I/2, § 17; íd., Die Menschlichkeit Gottes, Theologische Studien 48 (1956), 3-27.

(198) Cf. Wissenschaftstheorie, 308-309.

(199) Wissenschaftstheorie, 302.

(200) Ibíd., 302-303.

(201) Ibíd., 303.

(202) Cf. Ch. Mostert, God and the Future, 127-182.

(203) Die Frage, 386. 
poniendo al descubierto "la apertura del interrogar humano" (204). Como ya lo hemos señalado, nos hallamos aquí frente a una formulación muy sutil de la prueba ontológica, que, en una frase muy sintética y programática de su teología -tanto material como formalmente- Pannenberg resume de la siguiente manera: "la respuesta definitiva a la pregunta existencial del hombre es Dios mismo en el futuro de su soberanía (Herrschaft)" (205). El concepto de Dios como ente necesario se mantiene, pues, aunque hipotéticamente (206). Dios es la realidad que todo lo determina, incluida la misma pregunta humana sobre el sentido último de su existencia y de toda la historia. Dios, por su condición de respuesta, incita desde dentro al hombre a la "búsqueda de Dios" (207). Aquí es posible constatar -y si en la frase anterior ocupamos la idea de intimar, es posible realizar quizá una analogía con Agustín (208) - una circularidad teocéntrica del proceso interrogador del hombre: el final, Dios como definitivo hallazgo (209), está implicado, presupuesto, ya desde el comienzo, explicándose así la teologización del horizonte de apertura, de trascendencia, del hombre. Esta teologización se puede resumir de la siguiente manera: la realidad del hombre está remitida ya desde el inicio hacia Dios; de aquí la posibilidad de la pregunta sobre Dios. Es aquí donde radica la ilación del "argumento ontológico", la implicación, con el "argumento teológico", la "anticipación".

En base a dicha ilación es cómo se lleva a cabo la "determinación" del ente necesario -Dios como realidad que todo lo determina- como "ente perfectísimo" en tanto "ente futuro": "El futuro de Dios traerá respuesta a la problemática de cada fenómeno del mundo de la naturaleza y de los hombres, problematicidad que permanece aún abierta en el fluir de la historia" (210). De ahí su carácter hipotético.

\section{La respuesta divina y la "mediación" de la historia de las religiones}

Una parte importante de la estructura del primer volumen de la Teología Sistemática de Pannenberg (211) y por ende de su teología en general, la constituye el capítulo tercero dedicado a tematizar la forma como la respuesta divina es mediada por la historia de las religiones, al ser esta la historia de la interrogabilidad e indigencias humanas (212). Por esto, señala Pannenberg, "cualquier doctrina filosofía sobre Dios que, partiendo de la interrogabilidad del ser humano y de lo finito en general, infiera retroactivamente la respuesta que en esa interrogabilidad se apunta como tendencia, siempre habrá de topar con aquellas respuestas que se han originado desde la experiencia histórica de la realidad sobre la que versa la pregunta

(204) Ibíd.

(205) Ibíd., 385.

(206) Cf. I. Kant, Kritik der reinen Vernunft, 551ss (A 571ss). 604ss (A 642ss).

(207) Die Frage, 385.

(208) Cf. Systematische Theologie 1, 105.

(209) Cf. Die Frage, 385; ver también, la recensión de R. Schwager a los tres volúmenes de la Teología Sistemática de Pannenberg en, Zeitschrift für katholische Theologie 118 (1996), 505-508, sobre todo 505 .

(210) Die Frage, 386.

(211) Cf. J. A. Martínez-Camino, Aufhebung, 91-101.

(212) Cf. Systematische Theologie 1, 127-202 Die Frage, sobre todo 385-386; Anthropologie in theologischer, sobre todo, 77 ss. 236 ss. 
existencial del hombre, es decir, con las respuestas religiosas que, en cada uno de los casos, preceden ya a la reflexión filosófica y han sido por excelencia las primeras en irle descubriendo cada vez a esta reflexión una comprensión nueva de la interrogabilidad de la existencia" (213). Es interesante subrayar, como lo ha hecho recientemente una monografía dedicada a analizar las similitudes y diferencias entre los planteos de Rahner y Pannenberg (214), de qué forma en este punto se separa este último de Rahner y su desarrollo de una teología de la anticipación basada en una antropología trascendental (sobre todo la expuesta en Oyente de la Palabra), a pesar que Pannenberg reconoce su admiración por Rahner y su intento de mediar entre fe y razón bajo las condiciones de la Modernidad.

La respuesta de Pannenberg a la cuestión sobre la concentración antropológica de la teología está radicada en una antropología histórica, informada por la historia de las religiones, y la pregunta de Dios se resuelve, aunque problemáticamente, en la cuestión del futuro absoluto del hombre. Como lo expresa con claridad Pannenberg en un texto programático del inicio de su obra y que un método diacrónico de lectura de su obra permite constatar una coherencia y una constante de esta idea: "La respuesta definitiva a la pregunta existencial del hombre es, por tanto, Dios mismo en el futuro de su soberanía, la cual consistirá en la definitiva revelación de su divinidad, ya que esta coloca la historia del mundo a la luz del fin y, de esta forma, decide y desvela el significado, la esencia, de cada uno de sus rasgos particulares, de cada una de sus figuras y acontecimientos, manifestando así al Dios venidero (kommenden Gott) como Señor de todas las cosas" (215).

Aquí nuevamente es preciso señalar que desde el punto de vista del programa teológico de Hegel -y cabría añadir de la hermenéutica de la historia de Dilthey (216)-, este juega, no sin una interpretación crítica del filósofo idealista por parte de Pannenberg, un rol clave en la elaboración de su programa teológico: interpretar la historia en su totalidad como progresiva revelación de Dios. La historia es así prueba de Dios, "teodicea" (217).

Antes de pasar a las breves conclusiones crítico-prospectivas, caracterizaremos la teología hermenéutica de Pannenberg en dos afirmaciones fundamentales que se mantienen, con algunas variaciones, a lo largo de su obra: a) La historia en su totalidad no es comprensible sin una unidad: Dios como realidad que todo lo deter-

(213) Die Frage, 380.

(214) Cf. H. Springhorn, Immanenz Gottes und Transzendenz der Welt. Eine Analyse zur systematischen Theologie Karl Rahner und Wolfhart Pannenberg, Hamburgo 2001, sobre todo el "Excurso" sobre la recepción pannenbergiana de Rahner (475-497).

(215) Die Frage, 384. Esta idea se puede reencontrar como eje de la argumentación pannenbergiana - con clara influencia diltheyana- en todas sus grandes obras y, de forma sintética en, Sein und Zeit, en: Metaphysik und Gottesgedanke, 52-65; Begriff und Antizipation, en: ibíd., 66-79; para el seguimiento de esta idea, cf. Ch. Mostert, God and the Future, sobre todo los capítulos 3-5.

(216) Para la recepción crítica de Hegel en la obra de Pannenberg cf., Ch. Axt-Piscalar, Die Eschatologie in ihrer Funktion und Bedeutung für das Ganze der "Systematische Theologie" Wolfhart Pannenbergs, Kerygma und Dogma 45 (1999), 130-142.

(217) Cf. Systematische Theologie 1, 269; ver también Theologie und Philosophie, sobre todo los capítulos 9-10. Ver igualmente, Systematische Theologie 2, 189-201, en donde el autor desarrolla profundamente las implicaciones entre teodicea, creación y conocimiento de Dios, en vistas a un discurso "intelectualmente responsable" sobre Dios en la actualidad. 
mina; $b$ ) puesto que la historia está aún en marcha (en proceso, ocupando una expresión de Whitehead, con respecto al cual Pannenberg hace una lectura muy crítica, pero de la cual rescata el elemento procesal), la unidad de su totalidad solo es comprensible -interpretable- por la anticipación (prolepsis) de su fin, de ahí que su futuro en plenitud -Dios- antecede todavía con un rostro humanamente imprevisible (teología problemática). La historia en su totalidad es manifestación de Dios, pero como todavía no ha concluido en su proceso, únicamente desde el final será cognoscible como revelación. La revelación, en cuanto automanifestación de Dios, solo puede ser posible allí donde el todo de la historia es comprendido como revelación -con lo que llegamos al "círculo hermenéutico": creer para comprender, comprender para creer- y que la plena automanifestación de Dios "no tiene lugar en el comienzo, sino al final de la historia reveladora" (218), de ahí que Dios sea el Dios del futuro.

Una de las intenciones fundamentales pues de Pannenberg es realizar una "teología de la historia universal", la cual se presenta como una aplicación y superación de la cosmoteología griega. Viene a sustituir al argumento cosmológico, el cual

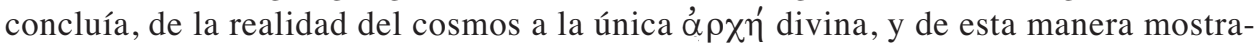
ba un monoteísmo cosmológico, por una teología basada en la historia, que, por el mismo procedimiento, concluía, de la unidad de la "realidad como historia", al Dios único de la historia (219). El método gnoseológico sigue siendo el mismo, solo que, en lugar del cosmos cerrado en sí mismo, que, en el eterno retornar de lo mismo, con su simetría y armonía, se convierte en teofanía, aparece en el pensamiento de Pannenberg un cosmos abierto al futuro, dotado de una propensión teleológica. La historia, se convierte así, subraya nuestro autor, en la síntesis de la realidad en su totalidad (220). De esta manera, en lugar de la cúspide metafísica de la unidad del cosmos, aparece el punto escatológico de la historia en que esta alcanza su unidad y conquista su meta. Así como desde aquella cúspide metafísica de unidad podía conocerse el cosmos como revelación indirecta de Dios, así ahora al final de la historia, se puede conocer la historia como revelación indirecta de Dios (221). Pannenberg concibe de esta manera la historia como teofanía indirecta y el método que utiliza es el método regresivo, el ir hacia atrás a fin de vincular empírica y racionalmente a Dios con la historia, más exacto aún, con la antropología histórica. Según estos planteamientos, fuertemente influenciados, como hemos señalado, por la hermenéutica diltheyana y el método popperiano, el conocimiento de Dios solo resulta posible post festum y a posteriori, volviendo la mirada hacia atrás, hacia los hechos

(218) Dogmatische Thesen zur Lehre von der Offenbarung, en: Offenbarung als Geschichte, Göttingen 1961, 95; cf. G. Cannobio, Uno sguardo complessivo sulla teologia del '900, en: íd., (ed.), Associazione Teologica Italiana. Teologia e storia: l'eredità del '900, Milano 2002, 7-32, sobre todo 23-27; A. Torres Queiruga, Fin del cristianismo premoderno. Retos hacia un nuevo horizonte, Santander 2000, 40ss.

(219) Cf. Die Aufnahme; 307-308; Systematische Theologie 1, 252-279; Offenbarung, 104; Heilsgeschehen und Geschichte, 22-78.

(220) Cf. Heilsgeschehen, 22-78; Systematische Theologie 1, 252-279.

(221) Cf. Systematische Theologie 1, 252-279, sobre todo 267ss (ver nota 150); Systematische Theologie 3, 632ss; Offenbarung und "Offenbarungen" im Zeugnis der Geschichte, en: M. Seckler et al. (ed.) Handbuch der Fundamentaltheologie, vol. 2, 64-82. 
consumados y hacia los vaticinios cumplidos en la historia (222). De esta manera en el pensamiento de Pannenberg se da un contrapunto de empirismo y racionalismo (223), ya que su teología hermenéutica de la historia puede, en principio, ser verificada por la misma historia, tal cual lo expresa en su artículo programático Acontecimiento salvífico e historia (224).

\section{CONCLUSIÓN CRÍTICA Y PROSPECTIVA}

Creemos que el aporte de Pannenberg al quehacer teológico actual es muy rico, sugerente y novedoso en casi todos los aspectos de la teología. En este artículo solo nos hemos referido sintéticamente a su elaboración de las condiciones de una teología mediada, como desafío frente a la Modernidad (pensar por uno mismo, hacer uso de la propia responsabilidad, la obligación de fundamentación [Begründungspflicht], la inseguridad y la apertura a todas las exigencias de validez [Geltungsansprüche], la exigencia de legitimación del poder y formas de vida son algunas condiciones de la Modernidad (225)).

Desde una perspectiva ecuménica, creemos que su aporte puede ayudar a desarrollar y pensar mejor una idea, o si se quiere, una tarea, contenida en Fides et ratio: "Es ilusorio pensar que la fe, ante una razón débil, tenga mayor incisividad; al contrario cae en el grave peligro de ser reducida a mito o superstición" (226). Y más adelante en el mismo documento eclesial se hace una referencia explícita a la "metafísica" (que nosotros podríamos ampliar al pensar filosófico) como "mediación privilegiada en la búsqueda teológica" (227).

Por tanto la salvaguarda de la fe de tipo barthiano, sin ninguna mediación, a la cual hemos hecho alusión en este trabajo, necesitará de una crítica desde lo que hemos denominado "teología de la mediación" (228). Esta teología es un modo de

(222) Cf. Heilsgeschehen, 76; Systematische Theologie 1, 267-269; Ch. Mostert, God and the Future, 14ss.

(223) Cf. C. Schwöbel, Rational Theology in Trinitarian Perspective. Wolfhart Pannenberg's Systematic Theology, Journal of Theological Studies 47 (1996), 498-527.

(224) "Tal teología de la historia se diferencia del pensamiento tradicional de la historia sagrada en cuanto pretende ser verificable. [...] Una verificación mediante la prueba ulterior por observaciones particulares sin restricción alguna no puede esperarse de un esbozo teológico de la historia. $\mathrm{Su}$ capacidad para tener en cuenta todos los hallazgos particulares conocidos sería el criterio positivo de su verdad; como criterio negativo puede aplicarse la prueba de que sin sus afirmaciones específicas los hallazgos disponibles no se pueden explicar o al menos no en su totalidad" (Heilsgeschehen, 76-77; ver también ibíd., 77-78; Wissenschafstheorie, sobre todo el capítulo 6).

(225) Cf. Th. Meyer, Fundamentalismus, 157.

(226) Juan Pablo II, Fe y razón. Carta encíclica “Fides et ratio”, Madrid 1998, 17. Es interesante constatar la cercanía con las advertencias de Pannenberg con respecto a una fe que no piensa y que no razona, que se convertiría en "ciega ingenuidad, credulidad o incluso superstición", amenazando con transformar la convicción creyente en un anacrónico "asylum ignorantiae" (cf. The Revelation of God in Jesus of Nazareth, en: J. M. Robinson-J. B. Cobb [eds.], Theology as History, Nueva York 1967, 130-131).

(227) Ibíd., 112 (cursiva, CC). Un espléndido estudio con respecto a esto -con referencias a Pannenberglo ofrece L. Oeing-Hanhoff, Die Krise des Gottesbegriffs, Theologische Quartalschrift 159 (1979), 285-303, sobre todo 301 ss.

(228) Solo a modo de ejemplo de la aparición en nuestros días de una teología no "mediada" de corte barthiano (contraposición o separación razón-fe), se puede apreciar en, J.I. González Faus-I. Sotelo, ¿Sin Dios o con Dios? Razones del agnóstico y del creyente, Madrid 2002. 
pensar, de teologizar, frente a (y en) la "razón", que ofrece muchas posibilidades de ser desarrollada. En el caso de Pannenberg, es pensada desde la "identidad y la diferencia" o si se quiere, "la identidad en la diferencia" (lo cual determina en el curso de la evolución de una teología sistemática como la de Pannenberg, la forma de articular los dogmas a partir de su centro de gravedad, que es la encarnación como prolongación de la vida intratrinitaria). El futuro, como eje de la teología pannenbergiana, se piensa así desde una ontología de la "identidad" (la "fidelidad" de Dios a su señorío) como "garantía" a la confianza del hombre en su abrirse, en la experiencia, al futuro en la "diferencia" de la historia. Brevemente: la estructura formal de la teología pannenbergiana es un modo de pensar "mediado", en "identidad y diferencia", a Dios y la creación, la historia y el hombre; o dicho de otra forma, fe y razón, en donde esa "y" debe ser pensada también como un "en".

Con respecto a la "fidelidad" recién mencionada, en nuestro artículo hemos querido señalar cómo el concepto clave de "anticipación" permite afrontar de forma fructífera una serie de aporías que se le presentan a la teología frente a su diálogo con la Modernidad, cuando este concepto recoge, por un lado, la afirmación del "ya" de la salvación plena y por otro lado, sintoniza con la aspiración fundamental del pensamiento moderno, como lo es pensar el futuro como horizonte abierto de libertad plena en medio de la experiencia de la historia y la subsiguiente pregunta por la teodicea.

El planteo de Pannenberg ha suscitado sin embargo algunas interrogantes que solo presentaremos de forma sumaria:

1. ¿Solo el final da sentido a la secuencia? Este es uno de los aspectos centrales del pensamiento pannenbergiano de clara raíz diltheyana, del cual cabe preguntarse si siempre, tanto al nivel individual como colectivo esto es realmente así: ¿tienen todos los individuos y la historia, de forma más general, asegurada una tal experiencia final que ilumine el sentido final de los sucesos del pasado? Y también cabe cuestionarse si esta argumentación, da cuenta de la incondicional apertura del hombre a corresponder a la llamada -hic et nunc- de la realidad y de su propio carácter de abierto ¿no sufre el momento presente una cierta devaluación cuando está supeditado a un final que todavía no es, por más que este esté anticipado?

2. ¿Cuáles son los límites del lenguaje hipotético sobre Dios? Si bien el lenguaje hipotético sobre Dios está sólida y coherentemente fundamentado en Pannenberg, ¿no resulta quizá problemática la presentación de Dios como "hipótesis"? La problemática de la comprensión hipotético-anticipatoria de los seres se puede aclarar en su transposición a la ética. Como lo ha expresado de forma provocativa $\mathrm{R}$. Spaemann: "Por hipótesis nadie muere. Solo quien tiene una convicción 'dogmática', de que un torturador contradice de lleno los derechos humanos..., solo él tiene un fundamento para luchar con decisión contra aquel torturador, aun a costa de correr él mismo el riesgo, es decir, de llegar a ser él también víctima" (229).

3. ¿No introduce la influencia de Hegel en el pensar teológico una cierta oscilación en la afirmación de la positividad de Dios? Sin poder entrar de lleno en este complejo tema, a veces surge la pregunta que si, más allá de todos los recaudos

(229) Ende der Moralität?, en: P. Koslowski et al. (ed.), Moderne oder Postmoderne?, Weinheim 1986, 28. 
metodológicos y de la sólida argumentación de Pannenberg, no se produce a veces una cierta "oscilación" entre datos que afirman la absoluta positividad de Dios (como por ejemplo el subrayar la "creatio ex nihilo" frente a todo tipo de pensamiento que quiera hacer depender a Dios de la creación) y una cierta relación de "dependencia" entre la divinidad y su "señorío", por más que se nos haya anticipado la plenitud? Además de aquí surge otra interrogante, ¿no aparece a veces en la explicación sobre este señorío, demasiado influida por la concepción de un despliegue del "poder que todo lo determina", un cierto riesgo de "determinismo"?

4. ¿No produce la aspiración científico-universitaria de la teología un cierto "estrechamiento" a la visión del quehacer del teólogo? La obra Teoría de la ciencia y teología tiene un carácter programático (1973), que a veces puede actuar como un "molde" al cual deben adecuarse todos los datos de la teología; pero, ¿es siempre la revelación anticipación?, ¿se revela Dios siempre indirectamente?, ¿se puede distinguir siempre adecuadamente entre revelación y autorrevelación? ¿No deberá hablarse más bien que Dios siempre se revela él mismo, aunque en un "proceso" revelatorio, en el cual su presencia es sin embargo siempre actual y total, si no se quiere caer en un cierto "formalismo" a la hora de tratar sistemáticamente los datos de la exégesis? La reacción de Pannenberg frente a la desvalorización de lo histórico en el planteo de Bultmann, ¿no implicará que la necesidad de verificar (empíricamente, v. gr. racionalmente) en la historia los datos de la fe puedan llevar a planteos cuestionables -y problemáticos en el diálogo con las ciencias sociales- como lo es la "verificación" de la resurrección con el recurso al relato de la "tumba vacía"?

Por último, queremos plantear una pregunta que posibilite seguir pensando con y desde el planteo de Pannenberg y señalar con ello el necesario contrapunto de puntos de vista con respecto al único e inagotable objeto de la teología: ¿Es la afirmación de Dios o del Absoluto como "verdadero infinito" susceptible de ser pensada junto con otros "conceptos marco" o "condiciones mínimas" para hablar de Dios que permiten una teología de la "mediación" - es decir, de una teología razonable frente a la Modernidad-al interior de la válida y necesaria pluralidad teológica? Nosotros creemos que al interior de la riqueza de la pluralidad teológica, uno de los "conceptos marcos" o "condiciones mínimas" para un discurso racionalmente viable de Dios o el Absoluto (es decir "mediado") frente a la Modernidad que utiliza Pannenberg, como lo es el "verdadero infinito", quizá pueda ser complementado con el "concepto marco" de la "absoluta y completa libertad" que ha desarrollado H. Krings (230) (y que ha sido desarrollado en nuestros días por, entre otros, y con diversos acentos, P. Hünermann, G. Essen, Th. Pröpper y M. Striet). Si bien el concepto marco de "verdadera infinitud" ha mostrado todo su potencial en la teología pannenbergiana, comporta una cierta desventaja, pues parte de una contraposición -y cuando se está hablando de la libertad de Dios esto puede acarrear algunas dificultades- y no de algo absolutamente positivo. Nos parece que Dios, definido como "libertad plena" (vollkomene Freiheit) da cuenta de un acento, de una modulación, a forma de contrapunto, con la idea de "verdadero infinito", de un punto de partida positivo y que recoge y tematiza el núcleo (algo ciertamente subrayado por

(230) Cf. Freiheit. Ein Versuch Gott zu denken, en: íd., System und Freiheit. Gesammelte Aufsätze, Freiburg-München 1980, 161. 
Pannenberg) de la problemática de la Modernidad y el nihilismo adyacente a ella, como lo es la libertad en su relación a la apertura del hombre a la totalidad, su experiencia de finitud y al reconocimiento de los otros. Así, la tesis central de Krings, que una analítica de la libertad conduce al concepto de Dios como libertad plena, se convierte en una llamada de atención a cualquier análisis que no tenga como punto de partida la problemática ahí implicada. Estos conceptos marco (tanto en Pannenberg como en Krings) están sin embargo al servicio de la comprensibilidad (v. gr. humanidad) de la Revelación y apuntan a esta como el lugar donde acontece el desvelamiento definitivo de Dios como amor. Es con respecto a esto último sobre todo, donde el contrapunto mencionado hará repensar (y de hecho de eso se trata la teología, movilizar para pensar a Dios) de qué manera aquellos conceptos permiten una mayor accesibilidad a la realidad concreta y a la vez universal de aquel amor, en donde la idea de libertad para "reflexionar" la autorrevelación de Dios en la historia nos parece un punto de partida ineludible. Para Krings -en conexión con la doctrina trascendental de la libertad de Kant y Fichte- el vaciamiento de Dios se convierte en el necesario marco de referencia de la libertad finita. Por este camino se debe producir un fructífero diálogo con la idea de "infinito" de Pannenberg.

\section{RESUMEN}

Este artículo pretende analizar la obra de Pannenberg como teología de la mediación, cuya característica básica radica en aceptar el órdago lanzado por el ateísmo moderno (sobre todo de la hermenéutica de la sospecha), partiendo de los mismos presupuestos de este: la antropología. Por eso el centro de interés de la teología de este autor radica en mediar racionalmente fe y razón o, si se quiere, teología y antropología. El objetivo de este intento es hacer razonable la idea misma de Dios, como el poder que todo lo determina, para que la revelación de Dios en las religiones, y en especial la cristiana, que es el lugar donde se decide sobre la realidad de la divinidad, cuente con un ámbito de inserción al interior de las preguntas fundamentales del hombre. Se pretende así hacer una teología con identidad y relevancia.

\section{ABSTRACT}

The article analyses Pannenberg's work, as a theology of mediation, whose basic principle lies on the acknowledgment of the havoc caused by the modern atheism (mainly by the hermeneutics of suspicion), looking at it from its very underpinning: the anthropology. The centre of attention of his theological thought lies on a rational mediation of faith and reason, or rather theology and anthroposophy. He pursues to make the idea of God as the determining power reasonable for us, so that God's revelation in the religions, and especially in the Christian that is where the reality of his divinity is decided, may find a place for insertion in the fundamental human questions. Accordingly, he attempts to develop a theology with identity and relevance. 